\title{
Interleukin-8 Gene Induction in the Myocardium after Ischemia and Reperfusion In Vivo
}

\author{
Gilbert L. Kukielka, ${ }^{\star \ddagger}$ C. Wayne Smith, ${ }^{\ddagger \S}$ Gregory J. LaRosa, 'Anthony M. Manning, ${ }^{\star \star}$ Leonardo H. Mendoza, ${ }^{\star}$

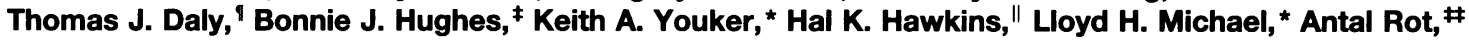 \\ and Mark L. Entman* \\ * Section of Cardiovascular Sciences, The Methodist Hospital, The DeBakey Heart Center and Department of Medicine, \\ ${ }^{\ddagger}$ Speros P. Martel Section of Leukocyte Biology, Department of Pediatrics, ${ }^{8}$ Department of Microbiology and Immunology and \\ "Department of Pathology, Baylor College of Medicine, Houston, Texas 77030; 'Departments of Molecular Biology and Biochemistry, \\ Repligen Corporation, Cambridge, Massachusetts 02139; **Upjohn Laboratories, Kalamazoo, Michigan 49001; \\ and ${ }^{\ddagger}$ Sandoz Research Institute, Vienna, Austria
}

\begin{abstract}
Neutrophil adhesion and direct cytotoxicity for cardiac myocytes require chemotactic stimulation and are dependent upon CD18-ICAM-1 binding. To characterize the potential role of IL-8 in this interaction, canine IL-8 CDNA was cloned and the mature recombinant protein expressed in Escherichia coli BL21 cells. Recombinant canine IL-8 markedly increased adhesion of neutrophils to isolated canine cardiac myocytes. This adhesion resulted in direct cytotoxicity for cardiac myocytes. Both processes were specifically blocked by antibodies directed against CD18 and IL-8. In vivo, after $1 \mathrm{~h}$ of coronary occlusion, IL-8 mRNA was markedly and consistently induced in reperfused segments of myocardium. IL-8 mRNA was not induced in control (normally perfused) myocardial segments. Minimal amounts of IL-8 mRNA were detected after 3 or $4 \mathrm{~h}$ of ischemia without reperfusion. Highest levels of induction were evident in the most ischemic myocardial segments. IL-8 mRNA peaked in the first $3 \mathrm{~h}$ of reperfusion and persisted at high levels beyond $24 \mathrm{~h}$. IL-8 staining was present in the inflammatory infiltrate near the border between necrotic and viable myocardium, as well as in small veins in the same area. These findings provide the first direct evidence for regulation of $\mathrm{IL-8}$ in ischemic and reperfused canine myocardium and support the hypothesis that IL-8 participates in neutrophil-mediated myocardial injury. (J. Clin. Invest. 1995. 95:89-103.) Key words: myocardial infarction - myocardial reperfusion injury $\bullet$ neutrophils $\cdot$ cell adhesion molecules $\cdot$ chemotaxis
\end{abstract}

\section{Introduction}

Substantial evidence indicates that chemotactic stimulation of CD18 adhesive functions is important in the mobilization of neutrophils into previously ischemic myocardium and in the

Address correspondence to Gilbert L. Kukielka, M.D., Section of Cardiovascular Sciences, Baylor College of Medicine, One Baylor Plaza, Houston, TX 77030. Hal K. Hawkins' present address is Department of Pathology, University of Texas Medical Branch, Galveston, TX 77555.

Received for publication 13 June 1994 and in revised form 29 August 1994.

J. Clin. Invest.

(c) The American Society for Clinical Investigation, Inc.

0021-9738/95/95/01/0089/15 \$2.00

Volume 95, January 1995, 89-103 extension of myocardial injury associated with reperfusion (1, 2 ). This concept is based on reductions in neutrophil accumulation and postreperfusion injury by $\mathrm{CD} 11 \mathrm{~b}$ and $\mathrm{CD} 18$ blocking mAbs in models of myocardial ischemia and reperfusion (310 ), as well as on the activation of complement after myocardial ischemia $(11-16)$. Furthermore, postischemic lymph is chemotactic for neutrophils as a result, at least in part, from C5a formation $(16,17)$. In addition to complement, other chemotactic factors likely play a role in this process (1). This is evidenced by recent studies where soluble complement receptor type-1, a potent inhibitor of both classic and alternative complement pathways, has failed to consistently inhibit neutrophil adhesion in reperfused myocardium $(18,19)$.

We have shown previously that endothelial cell monolayers incubated with postreperfusion cardiac lymph produced all the factors necessary to induce adhesion of unstimulated neutrophils $(20,21)$. Furthermore, when carefully observed under phasecontrast optics, a high percentage of neutrophils migrated beneath the endothelial monolayers, suggesting that activation of neutrophil motility had also occurred. Evidence provided by recent studies under similar in vitro conditions supports the conclusion that interleukin-8 (IL-8) may be directly responsible not only for inducing unstimulated neutrophil adhesion, but also for their transendothelial migration $(22,23)$. IL-8 has potent chemotactic and proinflammatory functions $(22-25)$ and is more selective for neutrophils than $\mathrm{C} 5 \mathrm{a}$, platelet-activating factor, or leukotriene $B_{4}(24,26)$. It appears that IL-8 is also important in activation of integrin adhesiveness and in directing leukocyte migration in vivo $(24,25,27)$. While the importance of IL-8 in models of ischemia and reperfusion has been recently suggested by the ability of anti-IL-8 antibodies to reduce lung parenchymal injury (28), the participation of IL-8 in similar models in the myocardium has not been explored. In this report we seek to $(a)$ characterize the role of recombinant canine IL8 in neutrophil activation, adhesion, migration, and adhesiondependent reactive oxygen formation; and $(b)$ establish the occurrence of IL-8 in post-reperfusion inflammation after coronary occlusion. The results in vitro demonstrate that IL-8 directly activates adhesion events and supports adhesion-dependent functions of the canine neutrophil. Our results also demonstrate that myocardial reperfusion initiates rapid induction of IL-8 in the previously ischemic tissue. Thus, IL- 8 may mediate activation of neutrophil adhesiveness and motility in the context of myocardial reperfusion.

\section{Methods}

Molecular cloning. A specific canine IL-8 cDNA probe was initially prepared by reverse transcription-PCR using RNA extracted from lipo- 
polysaccharide (LPS)-stimulated peripheral blood mononuclear cells Reverse transcription protocols were performed with $3 \mu \mathrm{g}$ of total RNA in each sample. After first strand synthesis primed with oligo dt, aliquots of the reverse transcription reactions were amplified with the following primers: 5' primer, 5'-GTGTCAACATGACTTCCAAACTG-3', 3' primer 5'-CTTCAAAAATATCTGTACAACCTT-3'; at a final concentration of $0.25 \mu \mathrm{M}$. PCR was performed with $5 \mathrm{U}$ of Taq polymerase (Promega Corp., Madison, WI) for 30 cycles of: $94^{\circ} \mathrm{C}, 30 \mathrm{~s} ; 55^{\circ} \mathrm{C}, 30$ $\mathrm{s} ; 72^{\circ} \mathrm{C}, 60 \mathrm{~s}$. The resulting 290 -bp amplified fragment was purified, cloned in pBluescript II SK- (Stratagene, La Jolla, CA) and sequenced. This PCR product was used to screen an oligo dt-primed cDNA library prepared from LPS-stimulated canine jugular vein endothelial cells (CJVEC) ${ }^{1}$ in the $\lambda$ ZAP II vector (Stratagene). Screening was performed by plaque filter hybridization methods (29). Filters were hybridized in rapid hybridization buffer (Amersham Corp., Arlington Heights, IL) at $65^{\circ} \mathrm{C}$ for $2 \mathrm{~h}$ and then washed with $1 \times \mathrm{SSPE}, 0.5 \%$ SDS at $65^{\circ} \mathrm{C}$ for $20 \mathrm{~min}$ followed by $0.5 \times \mathrm{SSPE}, 0.5 \% \mathrm{SDS}$ at $65^{\circ} \mathrm{C}$ for $20 \mathrm{~min}$. Isolated cDNA clones were purified and rescued in pBluescript SKusing the in vivo excision method. The complete nucleotide sequence of both strands of one clone (dIL-8-18) was determined using a combination of automated DNA sequencing on an automated DNA sequencer (model 373A; Applied Biosystems, Foster City, CA) and the dideoxynucleotide termination method (30). DNA sequences were analyzed using the suite of programs within EUGENE and SAM, as supported by the Molecular Biology Information Resource (Baylor College of Medicine, Houston, TX)

Synthesis of recombinant canine IL-8. Two canine IL-8 coding sequences were amplified in PCR reactions; one encoding an 80-amino acid protein starting at Ala23, a second encoding a 75-amino acid protein starting at Val28. Both have a Met start codon added to the amino terminus. The primers were: 5' primer (80) 5'-GTGGATATCAAGCTTCATATGGCAGTTCTGTCAAGAGTCAGT-3': 5' primer (75) 5'-GTGGATATCAAGCTTCATATGGTCAGTTCAGAACTTCGATGCC-3' ; 3' primer, 5'-GTGGATATCTCTAGAGGATCCTCATTATCACGGATCTTGTTTCTC- 3 '. These primers were used to amplify the above sequences using $1 \mathrm{ng} \mathrm{dIL}-8-18$ plasmid, $0.5 \mu \mathrm{M}$ primer, and $2.5 \mathrm{U} \mathrm{Taq}$ polymerase (Perkin-Elmer Corp., Norwalk, CT) for 30 cycles of: $94^{\circ} \mathrm{C}, 30 \mathrm{~s} ; 42^{\circ} \mathrm{C}, 30 \mathrm{~s} ; 72^{\circ} \mathrm{C}, 60 \mathrm{~s}$. The resulting 287 - and 272-bp amplified fragments were purified (QIAGEN Inc., Chatsworth, CA), digested with NdeI and BamHI, purified by agarose gel electrophoresis, and ligated with an NdeI-BamHI-digested, modified pET3a expression plasmid (Novagen, Inc., Madison, WI). The sequences of isolated clones were verified by sequence analysis using Taq dyedeoxyterminator cycle sequencing (Applied Biosystems) and an automated sequencer.

Canine IL-8 protein was expressed in Escherichia coli BL21 cells in two, 1-liter shake flasks. Expression was induced by overnight incubation with $500 \mu \mathrm{M}$ isopropyl $\beta$-D-thiogalactopyranoside (IPTG), and the cells were harvested by centrifugation at $6,000 \mathrm{~g}$ before lysis. Cells were lysed by sonication in buffer containing $0.05 \mathrm{M}$ Tris- $\mathrm{HCl}(\mathrm{pH}$ 8.0), $5 \mathrm{mM}$ EDTA, $5 \mathrm{mM}$ DTT, $0.1 \%$ Triton X-100, and 0.1\% PMSF. After lysis, the sonicated material was centrifuged, and the pellet was resuspended in buffer containing $0.05 \mathrm{M}$ Tris- $\mathrm{HCl}(\mathrm{pH} 8.0), 6 \mathrm{M}$ guanidine- $\mathrm{HCl}, 50 \mathrm{mM}$ DTT. The resolubilized protein was dialyzed against buffer containing 0.05 Tris- $\mathrm{HCl}$ ( $\mathrm{pH} \mathrm{8.0)}, 8 \mathrm{M}$ urea, and loaded onto a S-Sepharose column equilibrated in $50 \mathrm{mM}$ Mes (pH 5.0), $8 \mathrm{M}$ urea. After loading, the column was washed with $50 \mathrm{mM}$ Mes ( $\mathrm{pH} 5.0)$ to remove the urea followed by an additional wash with buffer containing $50 \mathrm{mM}$ Mes ( $\mathrm{pH} 5.0$ ), $500 \mathrm{mM} \mathrm{NaCl}$. Fractions containing canine IL8 were subjected to overnight refolding in the presence of $1 \mathrm{mM}$ oxidized glutathione and $2 \mathrm{mM}$ reduced glutathione. Extent of refolding was

1. Abbreviations used in this paper: CJVEC, canine jugular vein endothelial cells; DCFH, 2', $7^{\prime}$ dichlorodihydrofluorescein diacetate; GAPDH, glyceraldehyde 3-phosphate dehydrogenase; ICAM-1, intercellular adhesion molecule-1; KLH, Keyhole Limpet hemocyanin; ZAS zymosan-activated dog serum. monitored by Poros analytical chromatography. Refolded dog IL-8 was subsequently purified by chromatography using $\mathrm{C} 4$ semi-preparative reverse phase HPLC using a $0-100 \%$ acetonitrile gradient in $0.1 \%$ TFA $/ \mathrm{H}_{2} \mathrm{O}$. Fractions containing canine IL- 8 were pooled and examined for purity by SDS-PAGE, analytical C4 HPLC, amino acid analysis, and $\mathrm{NH}_{2}$-terminal sequencing.

Determination of purity of canine $I L-8$. To confirm the identity of the purified protein and to assess the purity of the isolated protein species, electrospray ionization spectra were obtained. The electrospray ionization spectra were acquired by a single quadrupole mass spectrometer (Trio 2000; Fisons Instruments, Inc., Danvers, MA). The mass spectrometer was calibrated using horse heart myoglobin and scanned from $\mathrm{m} / \mathrm{z} 600$ to 1,600 in $10 \mathrm{~s}$. The lyophilized samples were dissolved to their final concentration in a $1 \%$ acetic acid, methanol/water $(1: 1, \mathrm{vol} /$ vol) mixture, which was also used as the electrospray carrier solvent. Protein solutions at concentrations of $10-50 \mathrm{pmol} / \mu \mathrm{l}$ were injected ( 10 $\mu \mathrm{l})$ into the ion source at a flow rate of $10 \mu \mathrm{l} / \mathrm{min}$.

Western analysis of canine $I L-8$. For analysis with $\mathrm{mAb} 5 \mathrm{E} 7$, chemokine protein samples $(2 \mu \mathrm{g})$ were electrophoresed on a $15 \%$ SDS polyacrylamide gel and subsequently blotted onto nitrocellulose matrix. After blocking, the blot was transferred to milk buffer containing $2.5 \mu \mathrm{g} / \mathrm{ml}$ 5E7 monoclonal antibody. After removing unbound antibody, the blot was developed by standard procedures. For analysis with a rabbit polyclonal antibody anti-canine IL-8 $0.5-\mu \mathrm{g}$ chemokine samples were electrophoresed on a $14 \%$ tricine SDS polyacrylamide gel (31) and transferred to Immobilon-P filter (Millipore Corp., Bedford, MA). After blocking, the filter was incubated with the polyclonal anti-IL-8 ( $5 \mu \mathrm{g} /$ $\mathrm{ml}$ ) for $1 \mathrm{~h}$. The filter was developed with enhanced chemiluminescence Western blotting analysis system (Amersham Corp.).

Neutrophil isolation. Canine neutrophils were isolated from citrate anticoagulated venous blood using techniques described previously for the isolation of human neutrophils (32). This yielded a preparation of cells $>95 \%$ neutrophils with $>99 \%$ viability. These cells were suspended in Dulbecco's phosphate-buffered balanced salt solution (PBS) and used within $4 \mathrm{~h}$.

Isolation of CJVEC. These cells were obtained by modification of the method of Ford (33), as described previously (21). For adhesion assays, second passage cells were obtained by scraping, seeded onto gelatin-coated $(0.1 \%) 25-\mathrm{mm}$ round cover glasses, and grown to confluence.

Isolation of cardiac myocytes. Previously described procedures were used $(20,21,34)$. Myocytes were isolated by retrograde perfusion of the canine myocardium through an aortic cannula. Perfusion with low calcium solution was followed by the addition of collagenase (120 U/ $\mathrm{ml}$, type III; Worthington Biochemical Corp., Freehold, NJ). Preparations with a viability of $>80 \%$ were used in incubation experiments. Cells were used within $5 \mathrm{~h}$ of isolation.

Shape change and chemotaxis assays. Shape change was determined on canine neutrophils as described previously $(16,17,35)$. Suspensions of canine neutrophils were exposed to canine IL- 8 for $5 \mathrm{~min}$ at $37^{\circ} \mathrm{C}$ and then fixed in $1.0 \%$ glutaraldehyde. The percentages of cells assuming spherical, ruffled, bipolar, and uropod configurations were then determined visually by phase-contrast microscopy $(\times 100)$. The percentages of cells displaying ruffled, bipolar, and uropod configurations were added and reported as percent responsive neutrophils. For all antibody blocking studies, canine IL-8 and mAb 5E7 were coincubated for 20 $\mathrm{min}$ at room temperature before addition of cells.

Chemotactic migration was determined using the leading front assay as previously described (35). Haptotactic migration was assessed by a modification to the method of Rot (36). For both assays blind-well chemotaxis chambers (NeuroProbe, Cabin John, MD) and 3- $\mu$ m pore filters (Millipore Corp.) were used. Neutrophils were allowed to migrate for $45 \mathrm{~min}$ at $37^{\circ} \mathrm{C}$. The filters were removed, stained, and examined under oil. The distance migrated was determined as the distance between the upper surface of the filter and the leading front. For haptotaxis assays, gradients were preformed across the filters by filling the bottom wells with the attractants, filling the top wells with PBS, and incubating the chambers at $37^{\circ} \mathrm{C}$ for $30 \mathrm{~min}$. After incubation, the chambers were 
disassembled, and the filters were taken out and thoroughly washed in PBS to remove the attractant not bound to the filter. The filters were then air dried and placed into a new chemotactic chamber.

$m A b s$. The murine anti-IL-8 mAbs 5E7 (IgG1) and 5G9 (IgG1) were made by immunizing Balb/c mice subcutaneously and intraperitoneally each with $40 \mu \mathrm{g}$ of human monocyte IL-8 in complete Freund's adjuvant. Mice were boosted 2 wk later with $20 \mu \mathrm{g} \mathrm{IL-8} \mathrm{each} \mathrm{as} \mathrm{above}$ except in incomplete Freund's adjuvant. At 4 wk a second boost of 40 $\mu \mathrm{g} \mathrm{IL-8}$ in PBS was administered via the tail vein and splenocytes were harvested $3 \mathrm{~d}$ later. $1.25 \times 10^{8}$ splenocytes were fused with $3.0 \times 10^{7}$ SP2/o myeloma cells by standard polyethylene glycol fusion. Hybridoma supernatants were tested for the production of IL-8 binding antibodies by ELISA with a 96-well plate coated overnight with $50 \mu \mathrm{l}$ of a 1 $\mu \mathrm{g} / \mathrm{ml}$ solution of human IL-8. Clones EU3.5E7 and EU3.5G9 were found to be producing an antibody that bound to the human $\mathrm{IL}-8$ and were subcloned by serial dilution. The anti-CD-11b mAb MY904 $\left(\mathrm{Fab}^{\prime}\right)_{2}$ was obtained from Lilly Research Laboratories (Indianapolis, IN). The anti-CD18 mAb R15.7 (IgG1) (34) was supplied by Dr. Robert Rothlein (Boehringer Ingelheim Pharmaceuticals, Inc., Ridgefield, CT).

Immunofluorescense flow cytometry. Cell surface expression of $\mathrm{CD} 1 \mathrm{lb}$ was assessed using saturating concentrations of the mAb MY $904\left(\text { Fab' }^{\prime}\right)_{2}\left(\mathrm{IgG}_{1}\right)$ (Lilly Research Laboratories). Binding was detected with a rabbit anti-mouse antibody labeled with FITC (Zymed Labs, Inc., South San Francisco, CA) capable of detecting $\left(\mathrm{Fab}^{\prime}\right)_{2}$ fragments. Analysis was carried out with a FACScan ${ }^{\circledR}$ (Becton Dickinson Immunocytometry Systems, Mountain View, CA). Results are expressed as increase in mean fluorescence intensity.

Canine neutrophil adhesion to CJVEC monolayers and proteincoated glass. Confluent monolayers of CJVEC on glass coverslips were inserted into adhesion chambers, and the adhesion of isolated canine neutrophils was visually determined under static conditions as previously described $(33,37)$. For adhesion to protein-coated glass, $25-$ mm round coverslips were spotted with $10 \mu \mathrm{l}$ of a Keyhole Limpet hemocyanin (KLH) solution (Sigma Chemical Co., St. Louis, MO) in PBS for $30 \mathrm{~min}$ at $37^{\circ} \mathrm{C}$, rinsed in PBS by dipping six times, and mounted into the adhesion chambers as described previously $(35,38)$. The percentage of neutrophils remaining attached to the CJVEC or to the KLH-coated glass was determined as described previously $(35,38)$.

Canine neutrophil-myocyte adhesion. Adhesion was determined visually under static conditions as described previously $(20,34)$. Myocytes were incubated in the presence or absence of human recombinant IL- $1 \beta$ (Genzyme Corp., Boston, MA) for $3 \mathrm{~h}$ at $37^{\circ} \mathrm{C}$ before addition of the neutrophils. Isolated canine neutrophils were prestimulated with canine IL-8 or $1 \%$ zymosan-activated dog serum (ZAS) prepared as described (17) before use in adhesion assays.

Adhesion-dependent oxidation. Adhesion-dependent oxidation was determined as described previously (39). Isolated myocytes were preincubated with human recombinant IL-1 $\beta$ as described above. Subsequently, they were loaded with $2^{\prime}, 7$ '.dichlorodihydrofluorescein diacetate (DCFH; Molecular Probes, Inc., Eugene, OR) for $20 \mathrm{~min}$ at $37^{\circ} \mathrm{C}$ and washed twice. DCFH-loaded myocytes were then suspended with canine neutrophils stimulated with canine IL-8 or ZAS, under identical circumstances to the protocol used for adhesion. Fluorometric studies were performed by monitoring cellular fluorescence in a fluorometer (Perkin-Elmer Cetus Instruments, Norwalk, CT; excitation $488 \mathrm{~nm}$ and emission of $521 \mathrm{~nm}$ ).

Ischemia-reperfusion protocols. Healthy mongrel dogs (15-25 kg) of either sex were surgically instrumented as described previously (21). Anesthesia was induced intravenously with $10 \mathrm{mg} / \mathrm{kg}$ methohexital sodium (Brevital; Eli Lilly and Co., Indianapolis, IN) and maintained with the inhalational anesthetic Isoflurane (Anaquest, Madison, WI). A midline thoracotomy provided access to the heart and mediastinum, and cannulation of the cardiac lymph duct was then performed (17). Subsequently, a hydraulically activated occluding device and a Doppler flow probe $(17,21)$ were secured around the circumflex coronary artery just proximal or just distal to the first branch. Indwelling cannulae, placed in the right atrium, left atrium, and femoral artery, allowed blood sampling and pressure monitoring as needed.

The animals were allowed to recover for $72 \mathrm{~h}$ before occlusion. Ischemia-reperfusion protocols were performed in awake animals as described $(17,21)$. Coronary artery occlusion was achieved by inflating the coronary cuff occluder until mean flow in the coronary vessel was zero, as determined by the Doppler flow probe. At the end of $1 \mathrm{~h}$, the cuff was deflated and the myocardium was reperfused. Reperfusion intervals ranged from 1 to $24 \mathrm{~h}$. Analgesia was accomplished with intravenously administered pentazocine (Talwin; Winthrop Pharmaceuticals, New York) $0.1-0.2 \mathrm{mg} / \mathrm{kg}$.

After the reperfusion periods, hearts were stopped by the infusion of saturated potassium chloride and removed from the chest for sectioning from apex to base into four transverse rings $\sim 1 \mathrm{~cm}$ in thickness. Tissue samples were isolated from infarcted or normally perfused myocardium based on visual inspection. Myocardial segments were immediately frozen in liquid nitrogen. Frozen tissue samples were homogenized and processed in a blinded fashion for RNA isolation and analysis. Duplicate samples fixed in $10 \%$ buffered formalin were processed for blood flow determinations using radiolabeled microspheres as described previously $(21,40,41)$. All animal protocols were approved by the appropriate institutional review committee and conform to institutional guidelines.

Northern blots. RNA was isolated from myocardial tissue segments or cultured CJVEC using the acid guanidinium phenol chloroform procedure (42). RNA (5-20 $\mu \mathrm{g})$ was electrophoresed in $1 \%$ agarose gels containing formaldehyde, then transferred to a nylon membrane (Gene Screen Plus; New England Nuclear, Boston, MA) by standard procedures $(21,29)$. Loading of RNA was monitored using ethidium bromide staining as well as by probing the nylon membranes with human glyceraldehyde 3-phosphate dehydrogenase (GAPDH). Membranes were hybridized in QuikHyb rapid hybridization buffer ( Stratagene), containing $\sim 1 \times 10^{6} \mathrm{dpm} / \mathrm{ml}$ random hexamer ${ }^{32} \mathrm{P}$-labeled canine IL-8 cDNA probe at $68^{\circ} \mathrm{C}$ for $2 \mathrm{~h}$. The canine IL- 8 cDNA probe consisted of a 1,100 -bp fragment from the 3 ' untranslated region, obtained by restriction enzyme digestion from the isolated cDNA clone. After washing filters were exposed to Hyperfilm-MP (Amersham Corp.) for 12-24 h. Analyses of radioactivity were performed on a blot analyzer (Betascope 603; Betagen, Waltham, MA) by scanning the blots for $90 \mathrm{~min}$.

Polyclonal antibody to canine IL-8. A polyclonal antibody to canine IL-8 was made by immunizing rabbits with a 26 -amino acid peptide from the $\mathrm{COOH}$-terminal portion of canine IL-8. The peptide extended from Lys69 to Lys94 and it was synthesized in a peptide synthesizer (model 430; Applied Biosystems), using Fmoc chemistry according to the manufacturer's instructions. Purity of the peptide was assessed by amino acid analysis and HPLC. Three chinchilla rabbits were immunized. Each received $170 \mu \mathrm{g}$ of peptide with $170 \mu \mathrm{g}$ of complete Freund's adjuvant divided into six intradermal sites. Rabbits were boosted according to the same protocol on days 9,15 , and 22 . On day 29 , the rabbits were killed. The serum was collected and in the first step desalted on Sephadex G25 column. The resulting peak was applied on DEAE Trisacryl $M$ anion exchange column. The antibody-containing fraction eluted with the flow-through peak at three times the sample volume.

Immunohistochemistry. Samples were obtained immediately after the heart was removed from the animal and consist of 2-3-mm-thick sections extending transmurally through the anterior and posterior papillary muscles and the interventricular septum, and adjacent sections were taken from the midmyocardium parallel to the surface. These were placed in plastic embedding molds (Miles Lab-Tek, Naperville, IL) with OCT compound (Miles Inc., Elkhart, IN) and rapidly frozen in isopentane cooled to its freezing point with liquid nitrogen. Blocks were transferred to dry ice and stored at $-70^{\circ} \mathrm{C}$. Frozen sections $6-\mu \mathrm{m}$-thick were cut in a microtome-cryostat at $-20^{\circ} \mathrm{C}$, fixed for $15 \mathrm{~min}$ in ethanol at $-20^{\circ} \mathrm{C}$, and then air-dried. Sections were pretreated for $30 \mathrm{~min}$ with $1 \%$ sodium metaperoxidate and for $30 \mathrm{~min}$ with $0.1 \mathrm{M}$ ammonium chloride, then incubated for 20 min with $1 \%$ goat serum to block nonspecific absorption. Sections were incubated with the polyclonal rabbit 


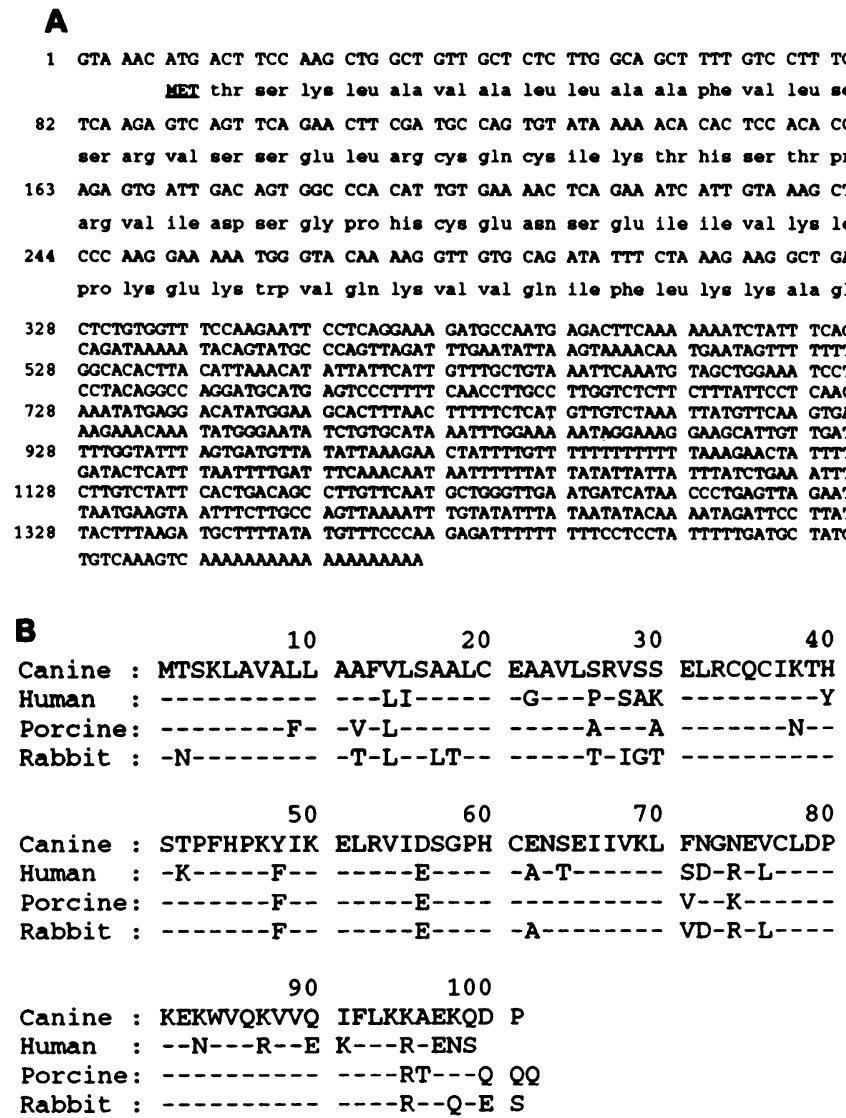

10

20

30

Canine : MTSKLAVALL AAFVLSAALC EAAVLSRVSS ELRCQCIKTH

Human : --

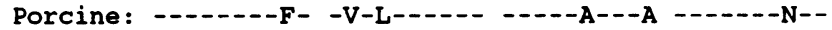

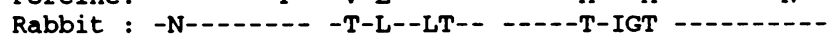

5

60

70

80

Canine : STPFHPKYIK ELRVIDSGPH CENSEIIVKL FNGNEVCLDP

Human : -K-----F-- $----\mathrm{E}-\cdots--\mathrm{A}-\mathrm{T}-----\mathrm{SD}-\mathrm{R}-\mathrm{L}----$

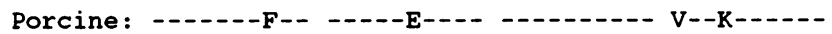

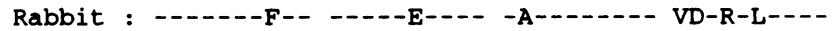

$90 \quad 100$

Canine : KEKWVOKVVO IFLKKAEKQD $P$

Human : - - N---R--E K---R-ENS

Porcine: -

Rabbit : -

antibody anti-IL-8 at $15 \mu \mathrm{g} / \mathrm{ml}$ for $1 \mathrm{~h}$ at $37^{\circ} \mathrm{C}$. After rinsing in PBS, the slides were incubated for $30 \mathrm{~min}$ with biotinylated, affinity-purified goat anti-rabbit IgG for $30 \mathrm{~min}$. The slides were rinsed in PBS and incubated for $45 \mathrm{~min}$ in $\mathrm{ABC}$ reagent (Vector Laboratories, Burlingame, CA) and then rinsed five times in PBS. Peroxidase was detected using diaminobenzidine, and the reaction product was intensified by rinsing with $1 \%$ osmium tetroxide. Slides were counterstained with hematoxylin and eosin.

\section{Results}

Library screening. A cDNA library that was prepared from poly (A) ${ }^{+}$RNA extracted from CJVEC which had been stimulated for $3 \mathrm{~h}$ with bacterial LPS was screened. 20 clones hybridized and contained inserts of 1.2-1.4 kb that upon Southern blotting demonstrated strong hybridization signals. The complete cDNA sequence of clone dIL-8-18, which appeared to contain the largest insert, was determined. Nucleotide sequence analysis revealed that the available canine IL- 8 cDNA sequence is $1,437 \mathrm{bp}$ in length, consisting of a $5^{\prime}$ untranslated region, a single open reading frame of $303 \mathrm{bp}$, and a $3^{\prime}$ untranslated area of $1,128 \mathrm{bp}$ excluding the poly $(\mathrm{A})^{+}$tail (Fig. 1). The open reading frame begins with the AUG start codon at position 7 and ends with the TGA stop codon at position 310 and encodes for a 101-amino acid precursor protein. This canine IL-8 clone has a short $5^{\prime}$ untranslated region. The nucleotide sequences in the vicinity of the AUG provide the context for translation initiation and are in agreement with many of the known consensus sequences present in eukaryotes $(43,44)$. Furthermore, the canine IL-8 initiation motif AACAUGA is identical to the hu-
Figure 1. (A) Complete cDNA and deduced amino acid sequence of canine IL-8. Both strands of cDNA clone dIL-8-18 were completely sequenced using a combination of automated DNA sequencing and the dideoxynucleotide termination method (see Methods). The sequence has been submitted under accession number U10308. The $\mathrm{NH}_{2}$-terminal Met is underlined and the consensus polyadenylation hexamer is double underlined. $(B)$ Protein sequence comparison. Canine, human (58), porcine (46), and rabbit (47) IL-8 amino acid sequences are compared. Identical amino acids are indicated with a dash. Percent amino acid identity to canine IL- 8 are 75,85 , and $80 \%$, respectively. All cysteine residues are conserved across the four species. man, porcine, and rabbit IL-8 homologues (45-47). After the $\mathrm{NH}_{2}$-terminal methionine, there is a positively charged 3-amino acid region that includes a lysine at amino acid position 4, followed by 15 hydrophobic residues, typical of $n$ and $h$ regions of a signal peptide (48). Based on the location of the $\mathrm{NH}_{2}$ terminal cleavage sites of human IL-8, the amino terminus of mature canine IL-8 could be at Glu21, Ala23, or Val28 (49, $50)$. Two putative signal peptidase cleavage sites that follow the $-3,-1$ rule were identified (48). These sites occur between residues 20 and 21 , or 22 and 23 , and would be compatible with two of the human IL- $8 \mathrm{NH}_{2}$-terminal forms. There is, however, significant evidence that IL-8 undergoes further $\mathrm{NH}_{2}-$ terminal processing after cleavage of the signal peptide (49, 50 ). In the case of human IL-8, a pentapeptide is proteolytically cleaved by thrombin in the presence of neutrophils (51). Similar processing would give rise to a mature canine IL-8 with an amino terminus at Val28. This mature protein (Val28-Pro101) does not contain $\mathrm{N}$-linked glycosylation sites. There are four cysteine residues accounting for 5\% of the total amino acids. These are predicted to be organized in two intrachain disulfide bridges. In addition, the first two cysteine residues of the mature protein conform to the $\mathrm{C} \times \mathrm{C}$ family characteristic. The $3^{\prime}$ untranslated region of canine $\mathrm{IL}-8$ is of similar length to that reported for human, porcine, and rabbit IL-8. It contains the eukaryotic consensus polyadenylation hexamer AATAAA (1416-1421), followed 16 bp downstream by a poly (A) ${ }^{+}$tail (52). A number of sequences that may be related to mRNA stability are present in the $3^{\prime}$ untranslated region of canine IL8: (a) 2 copies of the octamer UUAUUUAU (positions 810817 and 1075-1082) found in several unstable inflammatory 
A

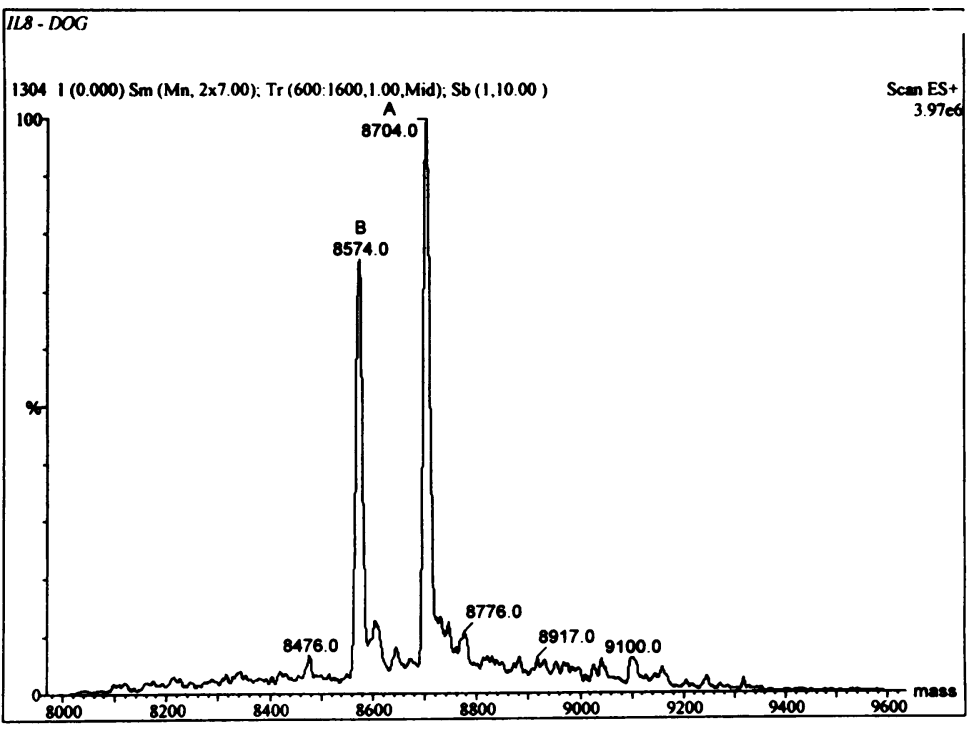

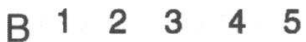

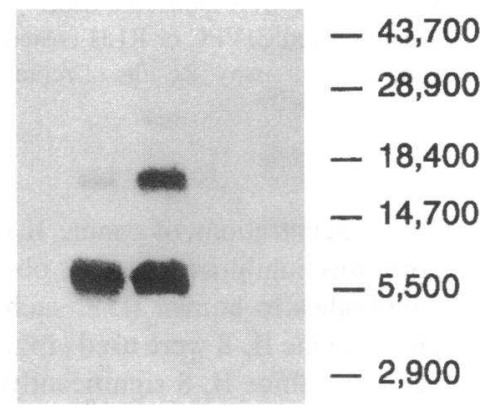

Figure 2. (A) Mass spectra of canine IL-8. Lyophilized samples of canine recombinant IL-8 were dissolved to their final concentration in a $1 \%$ acetic acid, methanol/water ( $1: 1$, vol/ vol) mixture, also used as the electrospray carrier solvent. Protein solutions $(10-50 \mathrm{pmol} / \mu \mathrm{l})$ were injected $(10 \mu \mathrm{l})$ into the ion source at a flow rate of $10 \mu \mathrm{l} / \mathrm{min}$. Two peaks that correspond to canine IL-8 with and without the $\mathrm{NH}_{2}$ terminal methionine are shown. $(B)$ Western analysis of canine IL-8 with 5E7. Chemokine protein samples $(2 \mu \mathrm{g})$ were electrophoresed on a $15 \%$ SDS polyacrylamide gel and subsequently blotted onto nitrocellulose matrix. The blot was probed with mAb 5E7 $(2.5 \mu \mathrm{g} / \mathrm{ml})$ as described in Methods. Designated lanes are as follows: 1 , platelet factor $4 ; 2$, canine IL-8; 3, human IL-8; 4, human GRO $\alpha$; and 5, molecular size markers. response mediators such as TNF- $\alpha$, GM-CSF, and c- fos (53, $54)$; (b) 1 copy of the sequence UAUUUAUUUA (positions 819-828) that is complementary to the consensus sequence of B2 elements (54); and (c) 10 copies of the pentamer AUUUA found in many cytokines and chemokines and capable of reducing mRNA stability $(55,56)$ and accelerating nuclear transport (57).

Canine IL-8 displayed significant sequence homology to human IL-8 at the amino acid level, being $75 \%$ identical overall. It also displayed high levels of amino acid homology to porcine and rabbit IL-8, being 85 and $80 \%$ identical, respectively (4547 ) (Fig. $1 B$ ). All cysteine residues are conserved across the four species. There is also remarkable similarity with human, porcine, and rabbit IL-8 in terms of the signal peptide length and sequence, position of the predicted signal peptidase cleavage sites, and total length of the proteins $(45-47,58)$.

Bacterial expression of canine IL-8. The recombinant protein was purified and refolded as described in Methods. Of the two coding sequences amplified, only the one encoding for the 75 -amino acid protein starting at Val28 was expressed. The purified canine IL-8 was further characterized to establish the authenticity of the cDNA clone and purity of the recombinant product. To provide estimates of molecular mass, electrospray ionization spectra were obtained (Fig. $2 A$ ). This technique allows mass estimation of high resolution and accuracy. The predicted molecular mass of the 75-amino acid canine IL-8 is
8,709 with the $\mathrm{NH}_{2}$-terminal methionine and 8,577 without this residue. Two peaks were identified with mass estimates of 8,704 and 8,574 . Within the $0.1 \%$ accuracy expected of this technique, these estimates correspond to the recombinant canine IL-8 with and without the $\mathrm{NH}_{2}$-terminal methionine. These findings were confirmed by $\mathrm{NH}_{2}$-terminal sequencing. Both forms of the recombinant canine IL-8 are present at almost equal proportions.

The corresponding Western blot performed with a murine monoclonal antibody to human recombinant IL-8 is shown in Fig. $2 B$. As shown, mAb 5E7 reacts with both recombinant human and canine IL-8. A dominant band of $\sim 8 \mathrm{kD}$, corresponding to the monomeric form of both molecules, was demonstrated. In addition, a 16-kD band corresponding to the dimeric form of IL-8 was observed in both species. This higher molecular band was more intense in the preparation of human IL-8. $5 \mathrm{E} 7$ did not recognize the related chemokines GRO $\alpha$ or platelet factor 4.

Biological activities of canine recombinant IL-8. Canine IL8 induced the typical shape changes observed in neutrophils in suspension after chemotactic stimulation. In Fig. $3 A$ the percentages of chemotactically activated neutrophils assuming ruffled and polar configurations increased after exposure to canine IL-8 in a dose-dependent fashion. Neutrophils responded to concentrations of recombinant canine $\mathrm{IL}-8$ as low as 0.03 $\mathrm{nM}$. The shape change induced by canine IL- 8 on neutrophils was specifically inhibited by mAb $5 E 7$ in a concentration-de- 

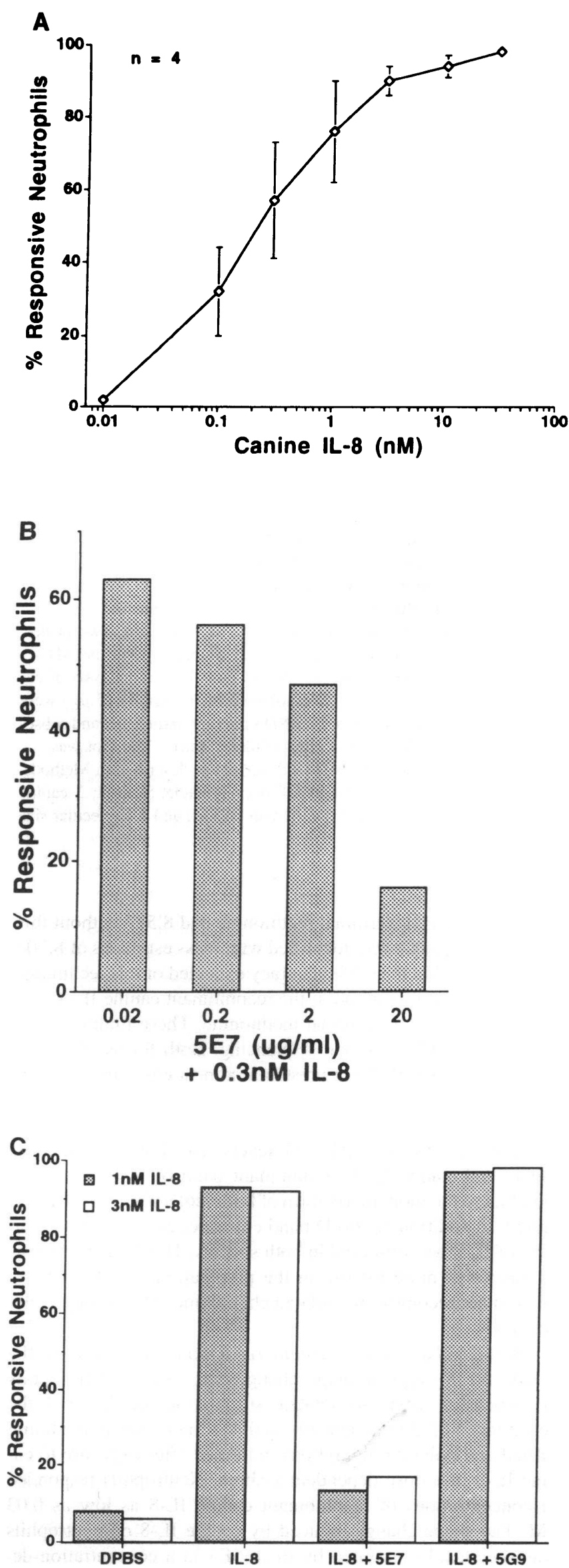

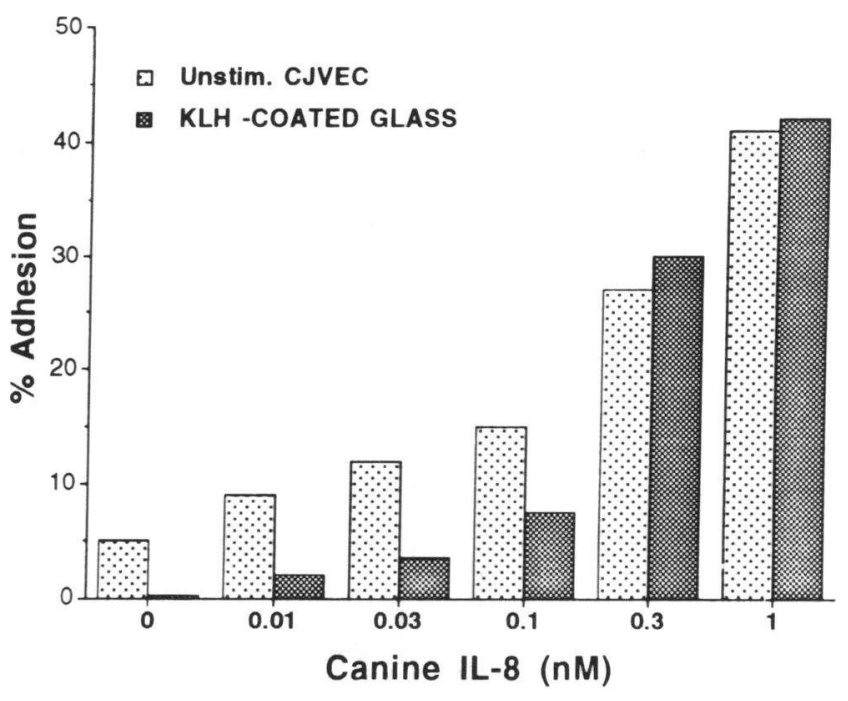

Figure 4. Stimulation of neutrophil adhesion by IL-8. Isolated canine neutrophils were incubated with an increasing concentration of canine IL-8. Cell suspensions were injected into the adhesion chambers and allowed to adhere to unstimulated monolayers of CJVEC or to KLHcoated glass, as described in Methods. Canine $\mathrm{IL}-8$ induced a dosedependent increase in adhesion to unstimulated CJVEC or KLH-coated glass. Adhesion was determined using a visual assay. Results of representative experiments are shown.

pendent manner (Fig. $3 \mathrm{~B}$ ) in all concentrations of canine IL8 tested (Fig. $3 C$ ). Furthermore, this inhibition was not observed when isotype-matched antibodies to human $\mathrm{IL}-8$, such as $\mathrm{mAb} 5 \mathrm{G}$, that did not recognize canine IL-8 were used (Fig. $3 C$ ). Stimulation of neutrophils with canine IL- 8 significantly increased adhesion to monolayers of CJVEC or to KLH-coated glass in a concentration-dependent manner (Fig. 4). Canine IL8 also increased the cell surface expression of $\mathrm{CD} 11 \mathrm{~b}$ on the neutrophil surface (Fig. 5), as reported previously for human IL-8 (59).

Exposure of neutrophils to IL-8 resulted in marked increases in adhesion to cardiac myocytes previously stimulated with IL$1 \beta$ to induce the surface expression of intercellular adhesion molecule-1 (ICAM-1) (Fig. 6 A). Peak adhesion was reached with $10 \mathrm{nM} \mathrm{IL-8.} \mathrm{As} \mathrm{shown,} \mathrm{levels} \mathrm{of} \mathrm{adhesion} \mathrm{induced} \mathrm{by}$ canine IL-8 were comparable to those observed after ZAS stimulation of the neutrophils. As previously reported, stimulation of both cell types appeared to be necessary since unstimulated neutrophils failed to adhere to IL-1-treated myocytes, and enhanced adhesion was not observed when IL-1 was omitted (34). Adhesion to cardiac myocytes was virtually eliminated when mAb R15.7 (anti-canine CD18) or mAb 5E7 was added to the reaction. Neutrophil-induced myocyte intracellular oxidative

Figure 3. Neutrophil shape change induced by canine IL-8. (A) Isolated canine neutrophils in suspension were incubated with varying concentrations of canine $\mathrm{IL}-8$ for $5 \mathrm{~min}$ at $37^{\circ} \mathrm{C} ;(B)$ with $0.3 \mathrm{nM}$ canine $\mathrm{IL}-8$ and increasing concentrations of $\mathrm{mAb} 5 \mathrm{E} 7$; or $(C)$ with 1 or $3 \mathrm{nM}$ canine IL-8 and $20 \mu \mathrm{g} / \mathrm{ml}$ of mAbs $5 \mathrm{E} 7$ or $5 \mathrm{G} 9$. Cells were subsequently fixed in $1 \%$ glutaraldehyde. Results are expressed as percent neutrophils demonstrating ruffled and polar configurations (\% Responsive Neutrophils) (mean $\pm 1 \mathrm{SD}, n$ represents the number of separate experiments). 


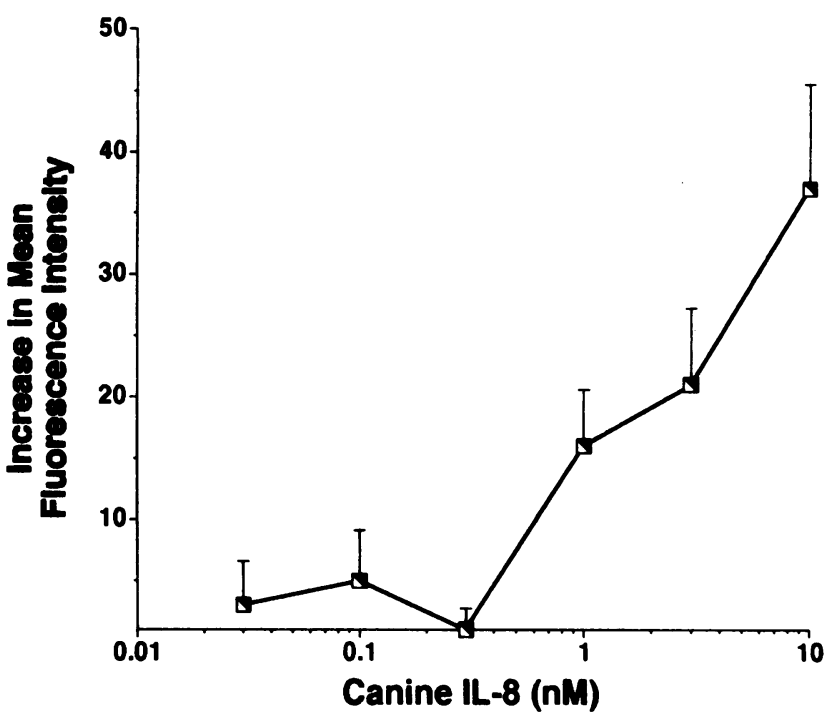

Figure 5. Cell surface expression of CD11b on canine neutrophils stimulated by IL-8. Isolated canine neutrophils were incubated with varying concentrations of canine $\mathrm{IL}-8$ for $5 \mathrm{~min}$. Cell surface expression of CD11b was assessed using saturating concentrations of mAb MY904 and ovaluated by flow cytometry. Bars indicate standard deviation, $n$ $=4$.

stress was studied using DCFH-loaded myocytes (39). As shown in Fig. $6 \mathrm{~B}$, increased fluorescence indicating intracellular oxidation of cardiac myocytes resulting from neutrophil adhesion occurred in response to canine IL-8. Fluorescence of DCFH-loaded myocytes was detected within 15 min after the addition of IL-8-stimulated neutrophils. In agreement with the adhesion data, fluorescence peaked when neutrophils were stimulated with $10 \mathrm{nM} \mathrm{IL-8.} \mathrm{In} \mathrm{addition,} \mathrm{peak} \mathrm{fluorescence} \mathrm{levels}$ observed with IL-8 stimulation were similar to those evident when ZAS was used as chemotactic agent. Fluorescence was also completely inhibited by mAbs R15.7 and 5E7 (data not shown).

As previously shown for human IL-8 (36), canine IL-8 induced neutrophil migration to haptotactic (filter-bound) and chemotactic (soluble) gradients (Fig. $7 \mathrm{~A}$ ). The haptotactic gradient of canine IL- 8 had similar potency and efficacy as the chemotactic gradient. As was the case with shape change, 5E7 almost completely inhibited the extent of neutrophil migration (Fig. 7 B).

Induction of IL-8 mRNA in CJVEC. Regulation of canine IL-8 mRNA was first studied in vitro in cultured CJVEC. The message was identified in Northern blot analyses as a $1.5-\mathrm{kb}$ hybridizing band (Fig. 8). Studies of the kinetic induction of IL- 8 mRNA by TNF- $\alpha$ revealed marked increases after $30 \mathrm{~min}$. Peak levels were reached after $3 \mathrm{~h}$ of stimulation. Steady state levels of IL-8 mRNA remained elevated above baseline levels even after $18 \mathrm{~h}$ of stimulation. This was consistent with the effects of TNF- $\alpha$ on human endothelial cells $(60,61)$. Minimal levels of IL-8 mRNA were occasionally detectable as a single species in untreated control samples. No differences in baseline expression were noted in samples of cells analyzed within the same experiment. In addition to the $1.5-\mathrm{kb}$ dominant band, a much weaker higher molecular weight band of $\sim 3.5-\mathrm{kb}$ was evident in analyses of stimulated but not unstimulated CJVEC. This band was similarly present in all cytokine-stimulated ca-
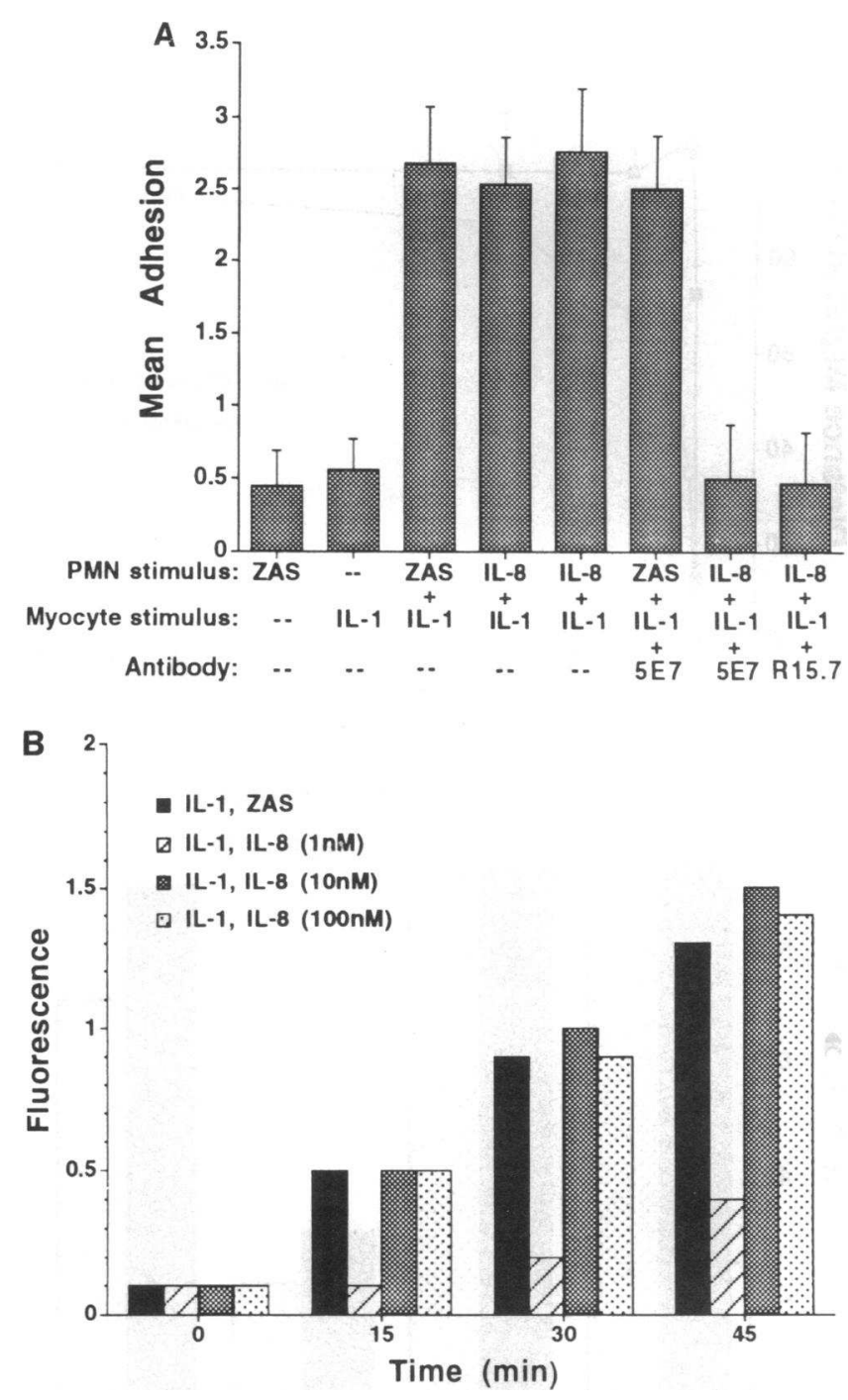

Figure 6. (A) Adhesion of neutrophils to cardiac myocytes induced by IL-8. Isolated canine neutrophils were stimulated with IL-8 (10 nM, lanes 4, 7, and 8; $100 \mathrm{nM}$, lane 5) or ZAS and added to cardiac myocytes that had been preincubated with and without IL-1 $\beta(4 \mathrm{U} / \mathrm{ml})$ for $3 \mathrm{~h}$ at $37^{\circ} \mathrm{C}$. At the end of the fourth hour of incubation, aliquots were visually evaluated for neutrophil-myocyte adhesion (expressed as mean number of neutrophils per myocyte). Both mAbs R15.7 (anti-canine $\mathrm{CD} 18$ ) and 5E7 (anti-IL-8) were used at $20 \mu \mathrm{g} / \mathrm{ml}$. Data are presented as mean $\pm 1 \mathrm{SD}$. $(B)$ Adhesion-dependent myocyte fluorescence. Isolated cardiac myocytes were preincubated with $\mathrm{IL}-1 \beta(4 \mathrm{U} / \mathrm{ml})$ for $3 \mathrm{~h}$ at $37^{\circ} \mathrm{C}$, loaded with DCFH as described in Methods, and washed twice. Loaded myocytes were suspended with neutrophils stimulated with IL8 or ZAS, at a ratio of 1:50. Fluorescence was determined using a fluorometer (Perkin-Elmer Cetus Instruments; excitation wavelength $488 \mathrm{~nm}$, and emission wavelength $521 \mathrm{~nm}$ ). Results are from a representative experiment.

nine cell types examined and in myocardial segments after ischemia and reperfusion (data not shown). However, relative to the major transcript, the intensity of this band was never $>5 \%$. This higher molecular weight band has also been observed in several human IL-8 studies in a variety of cell types (62-64).

Stimulation of IL-8 mRNA in CJVEC by postischemic cardiac lymph. Postreperfusion cardiac lymph elicited IL-8 mRNA when incubated with CJVEC in all samples tested, whereas no 

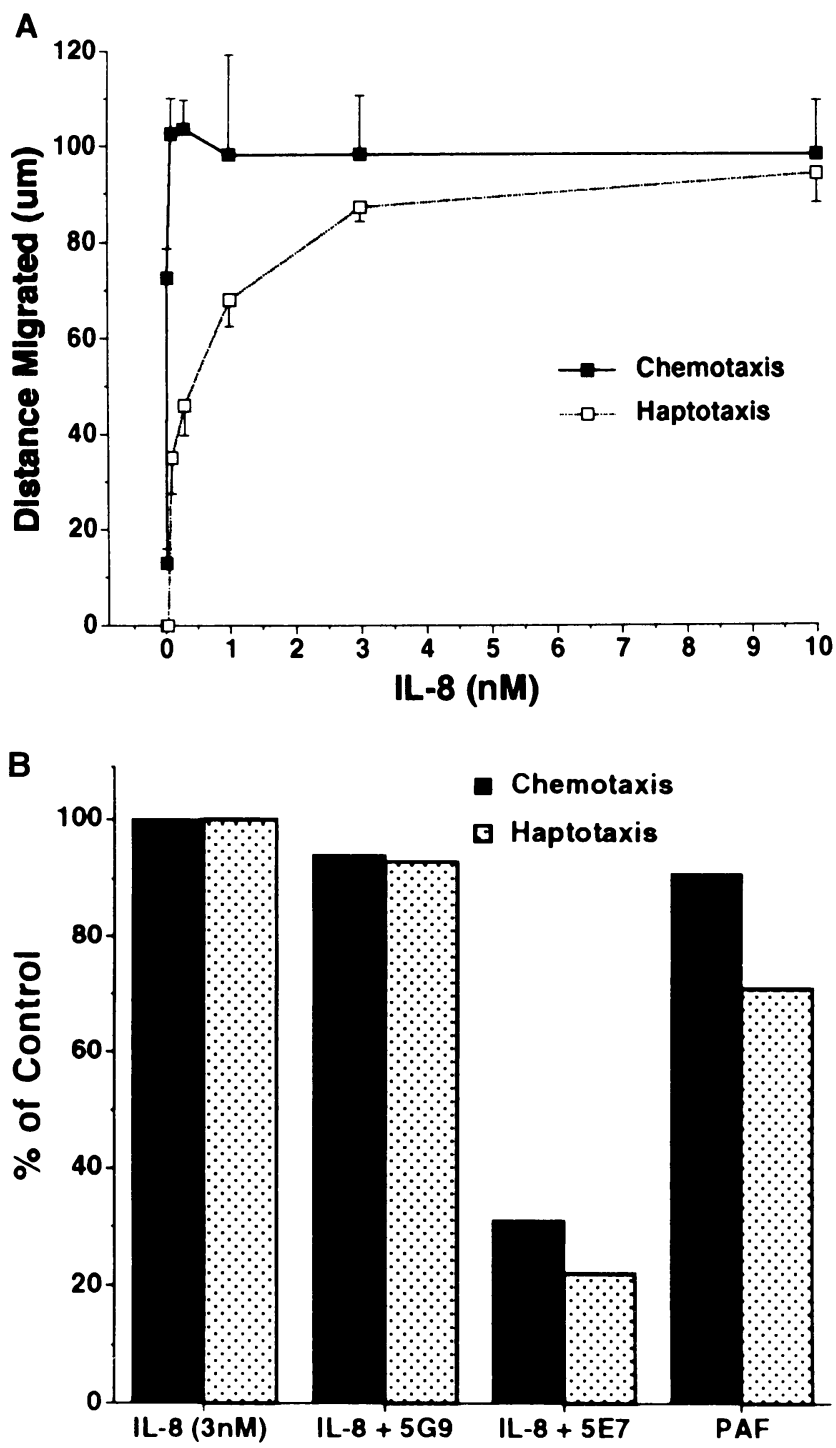

Figure 7. Neutrophil migration to chemotactic and haptotactic gradients of IL-8. (A) Chemotactic and haptotactic migration of isolated canine neutrophils in response to varying concentrations of canine IL- 8 were determined as described in Methods. Results are reported in microns migrated by the leading front of cells ( mean $\pm 1 \mathrm{SD}$ ). $(B)$ Effect of mAbs 5E7 and 5G9 on neutrophil migration. Antibodies $(20 \mu \mathrm{g} / \mathrm{ml}$ ) were coincubated with canine IL- $8(3 \mathrm{nM})$ for $20 \mathrm{~min}$ before addition to the chemotaxis chambers. Results are reported as the percent migration induced by canine IL- 8 . Platelet activating factor $(P A F)$ was used at $200 \mathrm{ng} / \mathrm{ml}$. Results of a representative experiment are shown.

specific stimulatory activity for IL-8 mRNA was present in preischemic lymph or in lymph collected during the occlusion period ( Fig. $9 \mathrm{~A}$ ). Factors in cardiac lymph responsible for the induction of IL-8 mRNA on CJVEC appeared to be produced or released as a consequence of myocardial ischemic injury. This conclusion is based on the fact that lymph obtained from an experimental animal that underwent coronary occlusion and reperfusion but did not develop a myocardial infarction did not elicit IL-8 mRNA when incubated with CJVEC (Fig. $9 B$ ). Peak stimulatory activity for IL-8 in postischemic lymph was found within the first $3 \mathrm{~h}$ of reperfusion (Fig. $9 \mathrm{C}$ ).

Induction of IL-8 mRNA in ischemic and reperfused myo-

\section{$\begin{array}{lllllllll}\text { Time (hr): } & & 0 & 0 & .5 & 3 & 6 & 12 & 18\end{array}$}

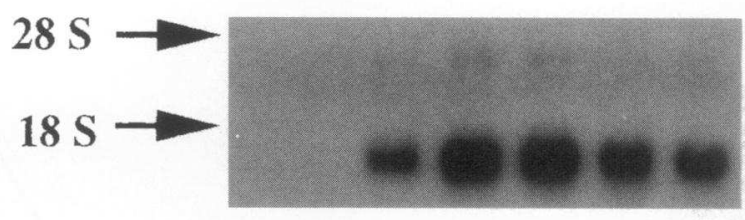

\section{Ethidium Bromide}

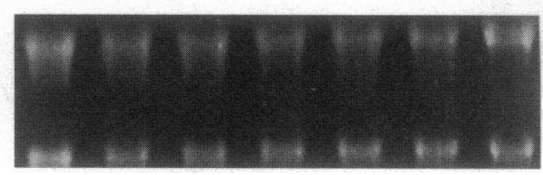

Figure 8. Regulation of CJVEC IL- 8 mRNA by TNF- $\alpha$. Total cell RNA was isolated from T-75 flasks of CJVEC after incubation in the presence or absence of TNF- $\alpha(30 \mathrm{U} / \mathrm{ml})$. A Northern blot containing $5 \mu \mathrm{g}$ of total RNA in each lane was equally loaded (as shown by the ethidium bromide staining ) and hybridized with a ${ }^{32}$ P-labeled canine IL-8 cDNA as described in Methods. The time course of steady state CJVEC IL-8 mRNA is demonstrated. Time of incubation in the presence of TNF- $\alpha$ is shown in hours: $0 \mathrm{~h}=$ control, unstimulated. The migration positions of the $28 \mathrm{~S}$ and $18 \mathrm{~S}$ rRNA bands are indicated. Equal loading was also verified by probing the membrane with human GAPDH (data not shown ).

cardium. To study the regulation of IL- 8 mRNA in ischemic and reperfused myocardium, we examined Northern blots of RNA isolated from myocardial segments characterized for their blood flow during coronary occlusion as described previously (21). Representative experiments in two animals subjected to $\mathrm{l} \mathrm{h}$ of coronary occlusion and $\mathrm{l} \mathrm{h}$ of reperfusion are shown in Fig. 10. In the experiment illustrated in lanes $C-G$, the animal sustained a large infarct. Significant induction of IL- 8 mRNA in all ischemic and reperfused myocardial tissue segments was observed ( lanes $D-G$ ). Highest levels of induction were present in segments demonstrating the lowest levels of blood flow ( lanes $D$ and $F$ ), whereas IL-8 mRNA was not detectable in normally perfused anterior ventricular wall segments as shown in lane $C$. Contrasting findings were evident in the experiment illustrated in lanes $A$ and $B$, which demonstrated no evidence of significant ischemia after the same coronary occlusion and reperfusion protocol. In this experiment, IL-8 message was not detected in any of the segments analyzed.

Regulation of myocardial IL-8 mRNA after I h of coronary occlusion and $l$ h of reperfusion. In a second set of experiments performed after $1 \mathrm{~h}$ of coronary artery occlusion and $1 \mathrm{~h}$ of reperfusion, a wide spectrum of induction of IL- 8 mRNA was observed. Four separate experiments are shown, each one identified by brackets at the bottom of Fig. 11. Concurrent assessment of myocardial blood flow indicated that the degree of ischemia was a major determinant regulating the levels of induction of IL-8 mRNA. The highest levels of induction in each separate experiment were generally evident in the most ischemic myocardial segments (Fig. 11, lanes $C, F, I$, and $O$ ). IL-8 mRNA was detected in segments with diminished levels of blood flow (Fig. 11, lanes $B, E, G, J, K$, and $M$ ), but was less intense than observed with more severe blood flow reductions. Furthermore, a graded response that closely paralleled the degree of ischemia in each individual segment was present. This concept is further 

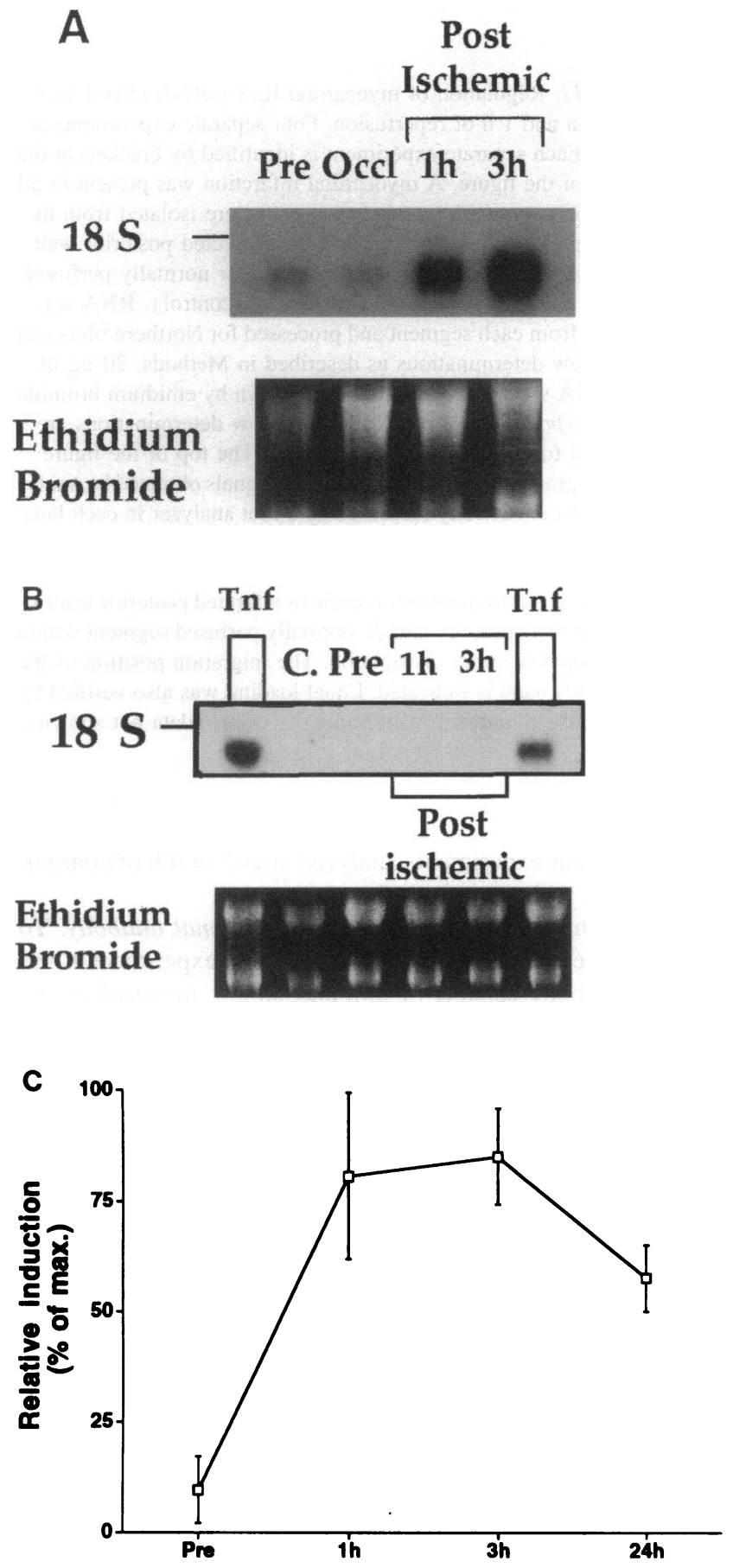

Figure 9. Stimulation of IL-8 in CJVEC by postischemic cardiac lymph. Aliquots of lymph were obtained from separate experiments before or during coronary artery occlusion and at designated times during reperfusion. In the experiment shown in $A$ the experimental animal was successfully infarcted, whereas in the experiments shown in $B$ the animal was not, despite undergoing identical occlusion protocol. Cultured CJVEC monolayers were preincubated with a 1:7 dilution of cardiac lymph or TNF- $\alpha(30 \mathrm{U} / \mathrm{ml}, B$, lane 1 or $10 \mathrm{U} / \mathrm{ml}, B$, lane 6$)$ for $3 \mathrm{~h}$ at $37^{\circ} \mathrm{C}$ in separate T-75 flasks. Cells were then used in Northern analyses loading $10 \mu \mathrm{g}$ of total RNA in each lane as shown by ethidium bromide staining (bottom). (C) Densitometric analyses demonstrating the relative levels of IL-8 mRNA induced on CJVEC by incubation with cardiac lymph obtained from three successfully infarcted animals. Data shown represent mean values of percent maximal induction assessed separately for

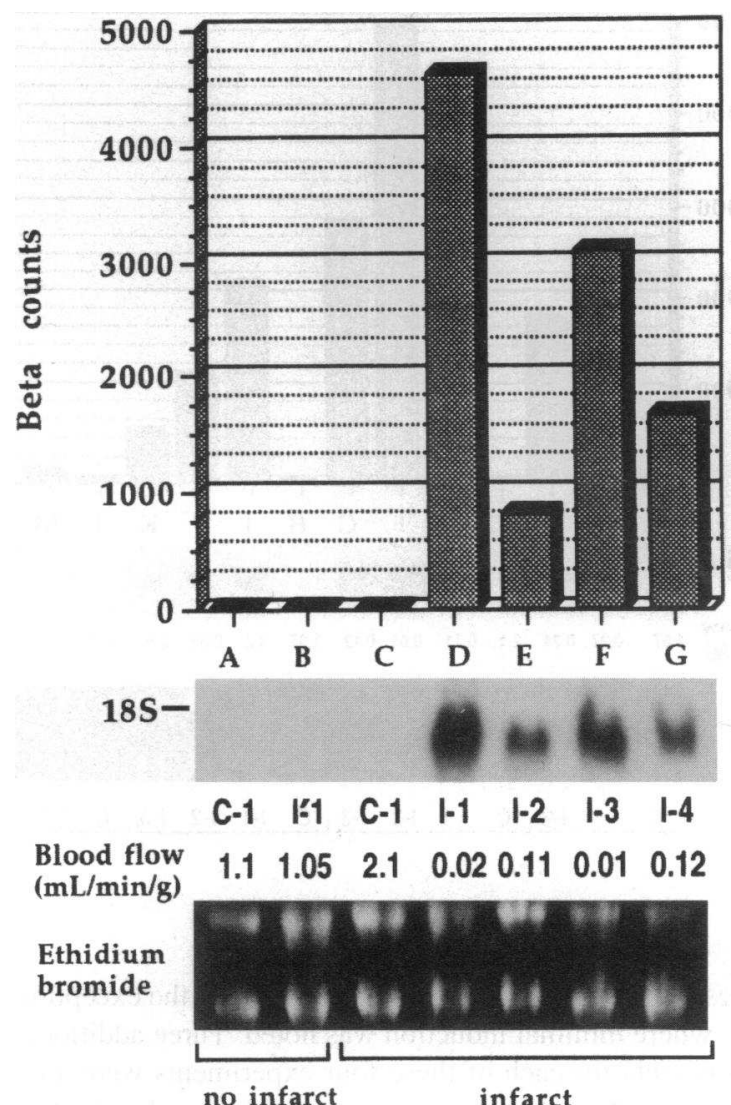

Figure 10. Induction of IL-8 mRNA in ischemic and reperfused canine myocardium. Experimental animals were subjected to $1 \mathrm{~h}$ of coronary occlusion followed by $1 \mathrm{~h}$ of reperfusion. A myocardial infarction was present in the experiment shown in lanes $C-G$, whereas no infarct was present in the experiment shown in lanes $A$ and $B$. Tissue segments were isolated from infarcted posterior papillary muscle and infarcted posterior wall (lanes $D-G$ ) or normally perfused anterior wall (lane $C$ ) of the first animal. Segments within the circumflex artery distribution (lane $B$ ) or normally perfused myocardium from the anterior wall (lane $A$ ) were isolated from the second animal. Segments are labeled $C$ for control, $I$ for ischemic and reperfused, or $I^{\prime}$ to indicate segments within the distribution of the occluded artery but without evidence of infarction. RNA was isolated from each segment and processed for Northern blots and blood flow determinations as described in Methods. $20 \mu \mathrm{g}$ of total RNA was loaded in each lane, shown by ethidium bromide staining (bottom). Endocardial blood flow determinations are indicated for each myocardial segment. The top of the figure shows a graphical representation of the signals obtained by analysis of the radioactivity measured by a blot analyzer in each lane. The position of the 18S rRNA band is indicated. Equal loading was also verified by probing the membrane with human GAPDH (data not shown).

supported by the finding of a graded response within each individual experiment and across every experiment examined when the data for all available segments were analyzed. Normally perfused control segments did not have a measurable induction

each experiment. Data are presented $\pm 1 \mathrm{SD}$. Equal loading was also verified by probing the membrane with human GAPDH (data not shown). 


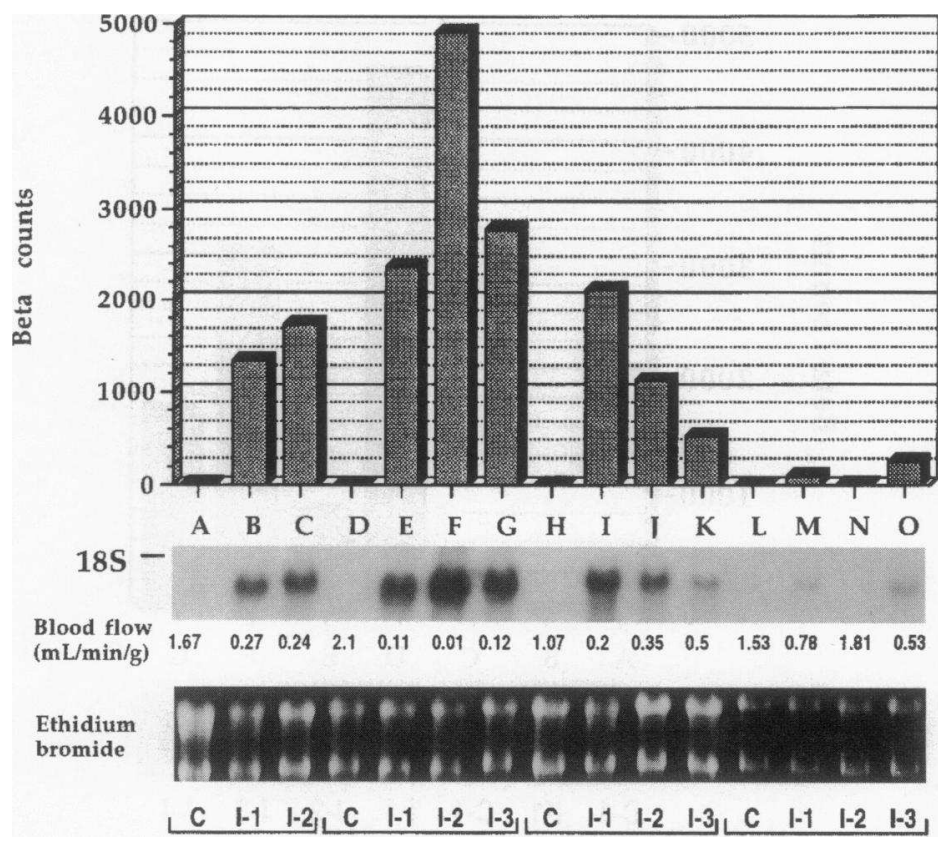

Figure 11. Regulation of myocardial IL-8 mRNA after $1 \mathrm{~h}$ of occlusion and $1 \mathrm{~h}$ of reperfusion. Four separate experiments are shown. Each separate experiment is identified by brackets at the bottom of the figure. A myocardial infarction was present in all four experiments. Myocardial segments were isolated from infarcted posterior papillary muscle and infarcted posterior wall (labeled $I$, for ischemic and reperfused), or normally perfused anterior wall myocardium (labeled $C$, for control). RNA was isolated from each segment and processed for Northern blots and blood flow determinations as described in Methods. $20 \mu \mathrm{g}$ of total RNA was loaded in each lane, shown by ethidium bromide staining (bottom). Endocardial blood flow determinations are indicated for each myocardial segment. The top of the figure shows a graphical representation of the signals obtained by analysis of the radioactivity measured by a blot analyzer in each lane. Designated lanes are as follows: lanes $A, D, H$, and $L$, normally perfused anterior wall; lanes $B, C, E, F, G, I, J, K, M$, and $O$, infarcted posterior papillary muscle or infarcted posterior ventricular wall myocardium; lane $N$, normally perfused segment within the circumflex artery distribution. The migration position of the $18 \mathrm{~S}$ rRNA band is indicated. Equal loading was also verified by probing the membrane with human GAPDH (data not shown). of this message (Fig. 11, lanes $D, H$, and $L$ ), with the exception of lane $A$, where minimal induction was noted. Three additional control segments for each of these four experiments were analyzed and failed to demonstrate measurable levels of IL-8 mRNA (data not shown).

Regulation of myocardial IL-8 mRNA: relationship to time of reperfusion. To directly evaluate the relationship of time and induction of IL-8 mRNA in ischemic and reperfused myocardium, a series of coronary occlusion experiments with varying intervals of reperfusion was compared. In all three experiments shown in Fig. 12, the circumflex artery was occluded for $1 \mathrm{~h}$, and then the myocardium was reperfused for 1,3 , or $24 \mathrm{~h}$. Myocardial infarctions were evident in all three experiments. A time-dependent induction of IL-8 mRNA was observed in ischemic segments analyzed among each of these three animals. When comparing segments with similar degrees of blood flow reduction, steady state levels of IL- 8 mRNA peaked within the first $3 \mathrm{~h}$ of reperfusion. IL-8 mRNA remained consistently elevated after $24 \mathrm{~h}$ of reperfusion, at levels as high as after the first hour of reperfusion. Expression of this message after 3 or $24 \mathrm{~h}$ of reperfusion was present only in ischemic and reperfused segments, whereas IL-8 mRNA was not evident in normally perfused anterior wall segments. Maximal induction was present in the most ischemic segments at all reperfusion intervals studied. Consistent with the observations after $1 \mathrm{~h}$ of reperfusion, experimental animals that were occluded and did not develop an infarct failed to demonstrate measurable induction of IL-8 mRNA at time periods up to $24 \mathrm{~h}$ (data not shown).

Regulation of IL-8 mRNA in the myocardium by reperfusion. The role of reperfusion in the induction of myocardial IL-8 mRNA was directly assessed in Fig. 13. In contrast to the ischemic and reperfused segments, nonreperfused segments after 3 or $4 \mathrm{~h}$ of ischemia demonstrated only minimal induction of IL8 mRNA, despite severe ischemia. The level of induction seen in the absence of reperfusion never exceeded $5-10 \%$ of equally ischemic segments with reperfusion. These findings are repre- sentative of four experiments analyzed after 3 or $4 \mathrm{~h}$ of continuous ischemia without reperfusion.

Development of anti-canine IL-8 polyclonal antibody. To evaluate the expression of IL-8 in the same experimental animals, an antibody capable of immunostaining myocardial sections was needed. A specific polyclonal antibody was made by immunizing rabbits with a synthetic 26 -amino acid peptide based upon the deduced amino acid sequence of the carboxy terminus of canine IL-8 (see Methods). This polyclonal antibody recognized recombinant canine IL- 8 in Western blots, without reacting with the related chemokine GRO $\alpha$ (Fig. 14). A much weaker band was also observed for human IL-8 (Fig. 14).

Distribution of IL-8 in ischemic and reperfused canine myocardium. Immunohistochemical studies of the IL-8 antigen in reperfused myocardium consistently showed distinct staining of the leukocytes which were present near the border between necrotic and viable myocardium (Fig. $15 \mathrm{~A}$ ). Staining of leukocytes was restricted to their cytoplasm. Staining of venular endothelium was also observed and was more often present in the vicinity of the inflammatory infiltrate than elsewhere. Positive staining of endothelium within small venules was often associated with the presence of neutrophils within the lumen or surrounding the vessel (Fig. $15 B$ ). Staining of arterial endothelium was not observed. After 1 or $3 \mathrm{~h}$ of ischemia without reperfusion staining for IL-8 was rarely seen (data not shown).

\section{Discussion}

Leukocyte migration into reperfused myocardium occurs in response to molecular events that signal injury or inflammation. In this report, we provide direct evidence that $\mathrm{IL-8}$ is induced in the myocardium as a result of experimental ischemia and reperfusion. These findings introduce a novel molecular signal present in reperfused myocardium and extend our previous ef- 

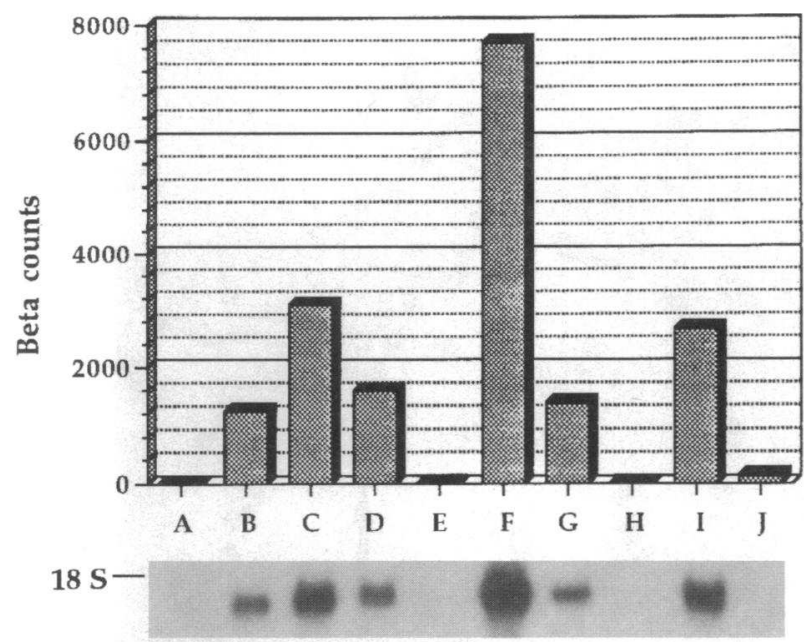

$\begin{array}{llllllllllllllll}\text { Blood Flow } & 2.1 & 0.11 & 0.01 & 0.12 & 2.26 & 0.11 & 0.24 & 1.77 & 0.01 & 0.81\end{array}$ $(\mathrm{ml} / \mathrm{min} / \mathrm{g})$

Ethidium bromide

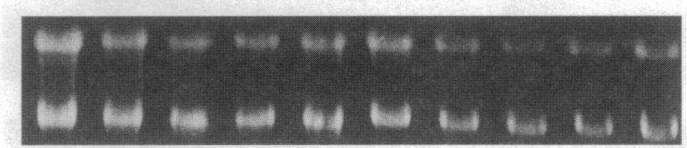

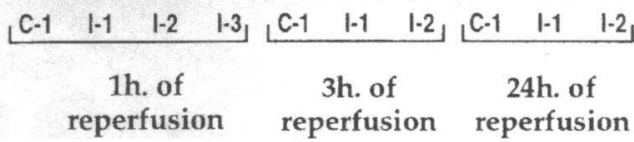

Figure 12. Regulation of IL-8 mRNA: relation to time of reperfusion. Three experimental animals were subjected to $1 \mathrm{~h}$ of coronary occlusion and 1,3 , or $24 \mathrm{~h}$ of reperfusion. Each experiment is identified by brackets at the bottom of the figure. Myocardial infarctions were present in all three experiments. Segments are labeled $C$ for control and $I$ for ischemic and reperfused. $20 \mu \mathrm{g}$ of total RNA was loaded in each lane. The top of the figure shows a graphical representation of the signals obtained by analysis of the radioactivity present in each lane. The migration position of the 18S rRNA band is indicated. Equal loading was also verified by probing the membrane with human GAPDH (data not shown).

forts to unravel the molecular pathophysiology of the inflammatory response that follows myocardial reperfusion injury.

Structural and functional comparisons demonstrate canine and human IL- 8 to be homologous proteins. Canine IL- 8 shares $75 \%$ identity with human IL-8. In addition to this high level of homology, there are also remarkable similarities in terms of signal peptide length and sequence, position of the predicted signal peptidase cleavage sites, and total length of proteins. All cystein residues are conserved across both species, including those that conform to the $\mathrm{C} \times \mathrm{C}$ family configuration. In vitro, canine IL- 8 has chemotactic and shape change dose-response profiles for canine neutrophils analogous to those of human IL8 for both human and canine neutrophils $(65,66)$. As shown previously for human IL-8, canine IL-8 induces changes in the surface expression and function of CD11b/CD18 and is capable of eliciting neutrophil migration not only in solution but also when bound to the surface of a chemotaxis filter $(36,59)$. Finally, epitope similarities were established by specifically blocking the neutrophil stimulation induced by canine IL-8 as well as by antigenic recognition in Western analysis by a monoclonal antibody made against human IL-8. Based on these observations, we conclude that the clone dIL-8-18 encodes for the canine homologue of human IL-8.

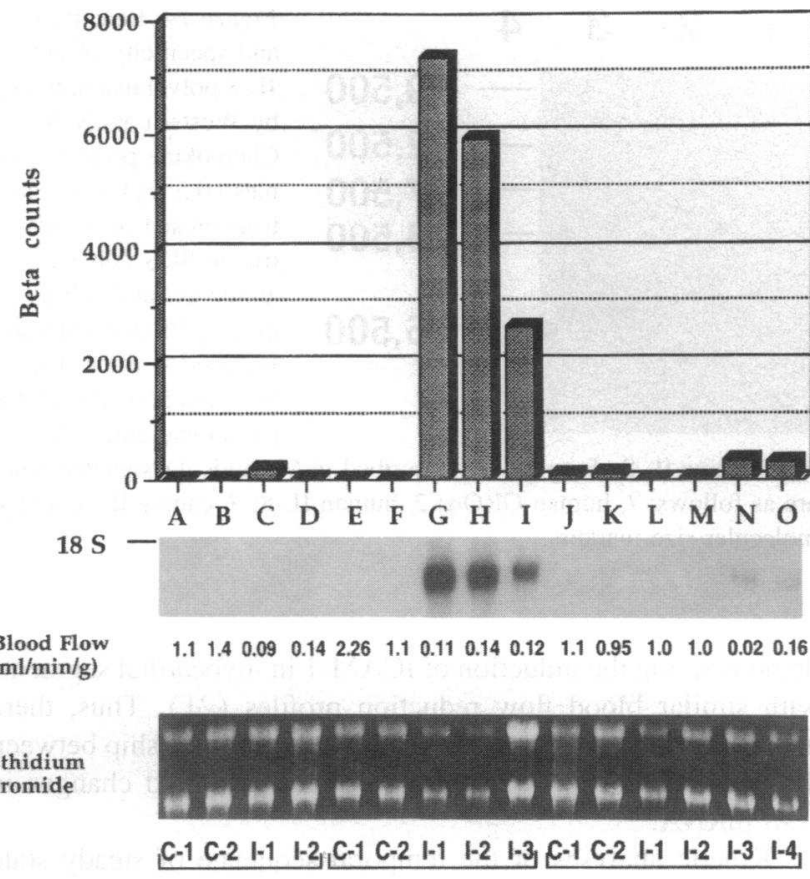

$\begin{array}{llll}\text { ISCHEMIA } 3 \mathrm{~h} . & \text { I/R } & 1: 3 & \text { ISCHEMIA } 4 \mathrm{~h} .\end{array}$

Figure 13. Regulation of IL-8 mRNA in the myocardium by reperfusion. Representative experiments in two animals subjected to 3 (left, lanes $A-D$ ) or 4 (right, lanes $J-O$ ) h of ischemia without reperfusion are shown. Each separate experiment is identified by brackets at the bottom of the figure. Levels of IL- 8 mRNA induced by ischemia alone are compared to the levels induced by $1 \mathrm{~h}$ of occlusion and $3 \mathrm{~h}$ of reperfusion (lanes $E-I$ ). All three animals sustained a large myocardial infarction. Myocardial segments are labeled $C$ for control and $I$ for ischemic or ischemic and reperfused, depending upon the experiment. RNA was isolated from each segment and analyzed using Northern blots and blood flow determinations as described in Methods. $20 \mu \mathrm{g}$ of total RNA was loaded in each lane, as shown by the ethidium bromide staining (bottom). Endocardial blood flow determinations are indicated for each myocardial segment. The top of the figure shows a graphical representation of the signals obtained by analysis of the radioactivity measured by a blot analyzer in each lane. The migration position of the 18S rRNA band is indicated. Equal loading was also verified by probing the membrane with human GAPDH (data not shown).

In these studies we documented that cellular events initiated by reperfusion of the previously ischemic myocardium consistently induced IL-8 mRNA in all segments that had been subjected to a significant degree of ischemia, while sparing the normally perfused control segments. The magnitude of blood flow reduction during coronary occlusion appeared to be a major determinant regulating the levels of IL-8 mRNA. The highest levels of induction were evident in the most ischemic myocardial segments. Furthermore, a graded response that closely paralleled the degree of ischemia was found in segments with mild and moderate reductions of blood flow. In animals in whom coronary occlusion did not affect ischemia because of extensive collateral blood flow, IL-8 mRNA induction was not detected. These findings were consistently evident regardless of the reperfusion interval. They are also in agreement with the observations of Dreyer et al. (8) who showed that the degree of neutrophil accumulation was inversely proportional to the regional myocardial blood flow during ischemia, and with our recent findings 


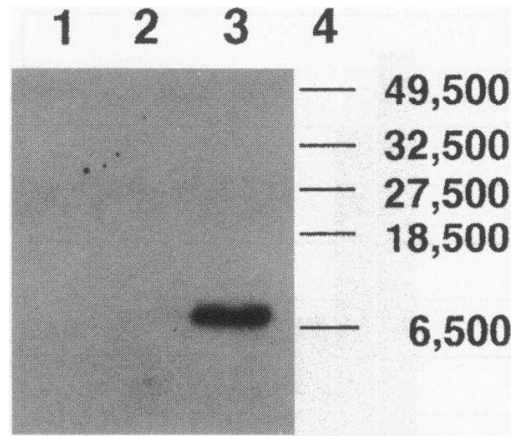

Figure 14. Reactivity and specificity of antiIL-8 polyclonal antibody by Western analysis. Chemokine protein samples $(0.5 \mu \mathrm{g})$ were electrophoresed on a $14 \%$ tricine SDS polyacrylamide gel and subsequently blotted onto an Immobilon filter. The blot was probed with the polyclonal antibody

anti-canine IL-8 $(5 \mu \mathrm{g} / \mathrm{ml})$ as described in Methods. Designated lanes are as follows: 1, human GRO $\alpha ; 2$, human IL-8; 3, canine IL-8; and 4, molecular size markers.

demonstrating the induction of ICAM-1 in myocardial segments with similar blood flow reduction profiles (21). Thus, there appears to be a quantitative and qualitative relationship between the degree of myocardial injury and the observed changes in IL-8 mRNA.

Kinetic analyses of the temporal sequence of steady state levels of IL-8 mRNA in ischemic myocardium after coronary reperfusion demonstrated remarkable similarities to the temporal sequence deduced by studying IL-8 mRNA induction on endothelial cells when incubated with postreperfusion lymph taken at similar time periods. These findings suggest the presence of soluble factors which induce IL-8 mRNA that may be operative with similar kinetics in vivo as well as in vitro as a result of myocardial reperfusion. Neutrophils and monocytes are known to produce IL-8 in response to a variety of soluble stimuli $(24,26)$, and leukocyte influx is markedly augmented by reperfusion; which may explain the observed relationship of IL-8 induction to myocardial reperfusion. Of particular interest is the observation that $\mathrm{C5a}$ induces $\mathrm{IL}-8$ on both neutrophils and monocytes (67). An alternative mechanism for IL-8 production involves signaling through a membrane protein that participates in the adhesive process. Recent evidence has implicated Lselectin as a molecule capable of transducing signals through a pathway that leads to transcription of IL- 8 and TNF- $\alpha$ in neutrophils (68). This finding is particularly relevant since L-selectin has been suggested to play an important role in neutrophil accumulation during myocardial reperfusion (69). Endothelial cells are also capable of producing IL- 8 when stimulated by a variety of soluble factors including TNF- $\alpha$ and IL- $1 \beta(24,61)$, as well as in response to anoxia (70). It is interesting to note that IL8 mRNA induction in neutrophils appears to last only a few hours, while levels of IL-8 mRNA on endothelial or mononuclear cells in response to cytokine stimulation remain elevated well beyond $24 \mathrm{~h}(24,62)$. Hence, it is conceivable that different cell types are responsible for the production of IL-8 at different times during reperfusion and that a number of induction mechanisms may be involved in this process.

While it has been suggested that the constitutively expressed ICAM-1 on endothelial cells may be sufficient to support CD18dependent transendothelial migration of neutrophils $(21,71)$, the requirement exists for a mechanism to direct neutrophil activation and transmigration to the injured areas of myocardium. Huber et al. (22) have shown that neutrophil transmigration across cytokine-stimulated endothelial cell monolayers occurs in response to a surface-bound IL- 8 produced by the endo-
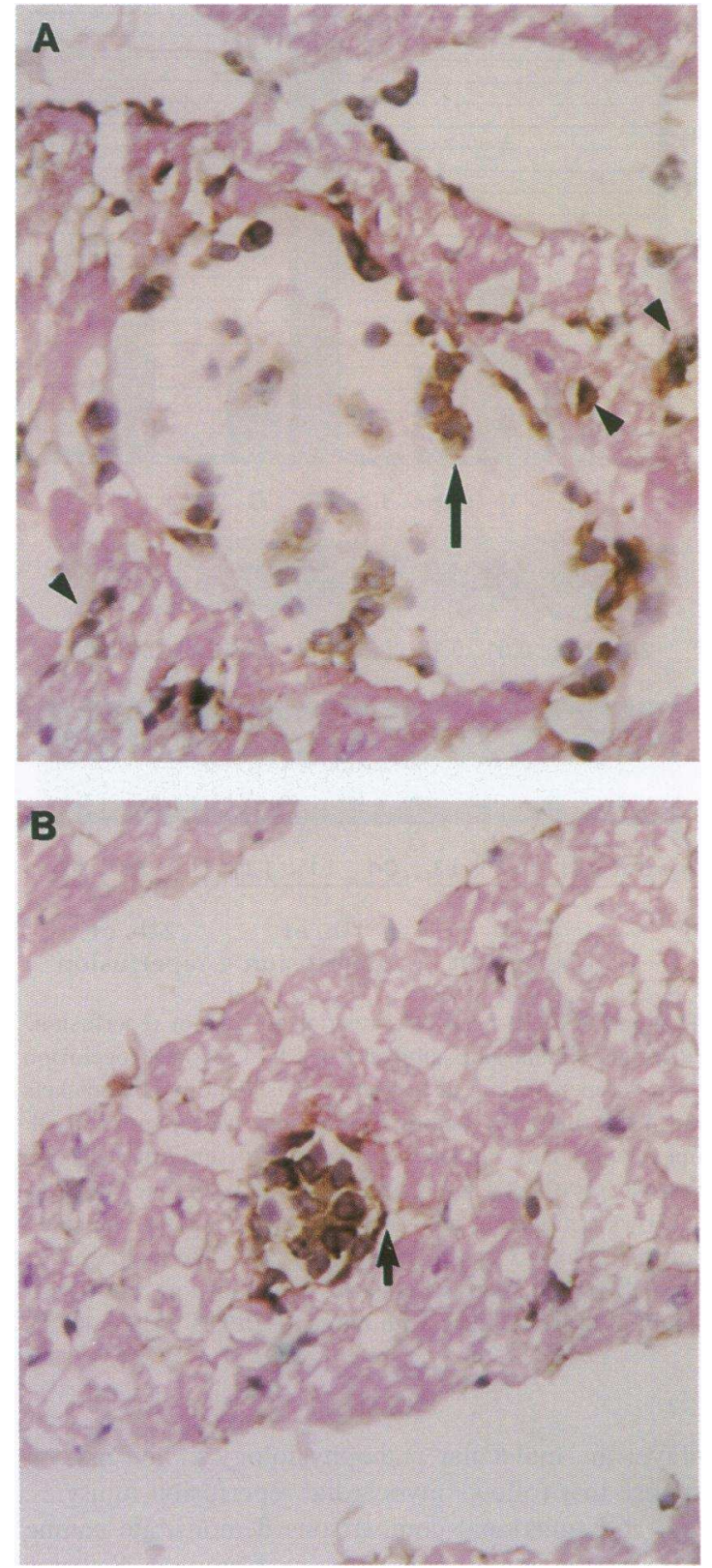

Figure 15. Distribution of IL-8 in ischemic and reperfused canine myocardium. Cryostat sections stained with the anti- $\Pi$ - 8 polyclonal antibody and counterstained with hematoxylin and eosin. The sections were taken from the posterior left ventricular wall $3 \mathrm{~h}$ after reperfusion of previously ischemic myocardium. $(A)$ Intense brown reaction product is present in the cytoplasm of leukocytes lining the luminal surface of veins (arrow) and extending between cardiac myocytes (arrowheads). $(B)$ Staining of venular endothelium was also observed (arrow) and was more often present in veins containing leukocytes than elsewhere.

thelial cells. However, no transmigration occurred when the gradient was disturbed by adding soluble IL-8 to the apical compartment. Hechtman et al. (72) showed that while intradermal injections of IL-8 induce neutrophil accumulation, intravascular administration does not. In a recent study Rot et al. (73) revealed the presence of IL- 8 binding sites present only on the luminal surface of postcapillary and collecting venules and small veins in the skin. These are the sites from which neutro- 
phils transmigrate into tissues and are analogous to those venular structures supporting neutrophil accumulation and transendothelial migration in reperfused myocardium (21). In our model, while IL-8 mRNA was not induced in normally perfused segments, expression of IL-8 mRNA in myocardial segments had a high degree of spatial and temporal correlation with the observed degree of ischemia and with our previous determinations of neutrophil sequestration in reperfused myocardium, respectively. High levels of $\mathrm{IL}-8$ protein were evident early in reperfusion, at a time when the rate of neutrophil accumulation in reperfused myocardium is maximal (8). Based on our results, it is reasonable to propose that $\mathrm{IL-8}$ constitutes a molecular signal that could contribute to the mechanism of neutrophil localization in early reperfusion.

IL-8 induced in the myocardium during reperfusion can serve as a stimulus for activation of neutrophil adhesiveness and cytotoxic behavior. Under static conditions and within a range of concentrations that increased the surface expression of CD18, canine IL-8 induced a concentration-dependent increase in the adhesion of canine neutrophils to $\mathrm{KLH}$-coated glass (a CD11b/CD18 substrate) and to unstimulated endothelial cells. A novel finding was the induction of IL-8-stimulated neutrophil adhesion to cardiac myocytes through a CD18-dependent mechanism. These observations are compatible with our previous studies demonstrating that neutrophil adhesion to cardiac myocytes requires chemotactic stimulation $(34,37)$ and that under conditions of ZAS stimulation this adhesion also requires CD18. Under similar stimulatory conditions, IL-8 induced neutrophil cytotoxicity for cardiac myocytes, as evident by intracellular oxidation of DCFH (39). Previous studies in our laboratories have shown that only conditions that promoted neutrophil-myocyte adhesion resulted in fluorescence of DCFHloaded myocytes (39), and that myocyte contracture consistently occurred a few seconds after the peak of fluorescence (39). Moreover, both adhesion and fluorescence depend primarily on CD11b/CD18 and ICAM-1 interactions $(34,37,39)$. Thus, IL-8 may participate in the neutrophil-induced myocardial injury by inducing ligand-specific adhesion to cardiac myocytes, which in turn is required for a compartmented transfer of reactive oxygen species to cardiac myocytes (39).

Taken together these findings confirm our hypothesis that IL- 8 is induced in reperfused myocardium and underscore the potential role of IL-8 in neutrophil activation and transmigration in previously ischemic myocardium. It is interesting to speculate that, under circumstances where blood flow may preclude the establishment of a stable soluble chemotactic gradient, a surface-bound chemoattractant may represent an effective mechanism of chemotactic agent presentation and of neutrophil activation. Parenchymal injury after lung ischemia and reperfusion has been prevented with the administration of anti-IL-8 antibodies (28). It remains to be seen whether the same protection would occur in the heart. The results in this report are also consistent with the interpretation that sequential and overlapping patterns of chemoattractant generation, with varying degrees of cell specificity, are likely to occur in vivo after reperfusion of the previously ischemic myocardium.

\section{Acknowledgments}

We acknowledge the excellent technical assistance of Jason Lai, Lynn Zuchowski, Hubert Jacshe, Lisa T. Thurmon, Peggy Jackson, Gary
Liedke, Jessica Zhu, and Qingyan Zhu, as well as the expert secretarial assistance of Lisa M. Padilla and Michelle Swarthout.

This work was supported by National Institutes of Health grants HL-42550, AI-23521, and HL-47163 and by a grant from The Methodist Hospital Foundation (G. L. Kukielka).

\section{References}

1. Entman, M. L., G. L. Kukielka, C. M. Ballantyne, and C. W. Smith. 1993. The role of leukocytes in ischemic heart disease. In Handbook of Immunopharmacology. C. Chapman, editor. Academic Press Ltd./Harcourt Brace Jovanovich, London. 55-74.

2. Kukielka, G. L., and M. L. Entman. 1994. Adhesion molecule-dependent cardiovascular injury. In Cellular Adhesion: Molecular Definition to Therapeutic Potential. G. Poste and B. Metcalf, editors. Plenum Publishing Corp., New York. 187-212.

3. Simpson, P. J., R. F. Todd, III, J. C. Fantone, J. K. Mickelson, J. D. Griffin, and B. R. Lucchesi. 1988. Reduction of experimental canine myocardial reperfusion injury by a monoclonal antibody (anti-Mol, anti-CD11b) that inhibits leukocyte adhesion. J. Clin. Invest. 81:624-629.

4. Williams, F. M., P. D. Collins, S. Nourshargh, and T. J. Williams. 1988. Suppression of $111 \mathrm{In}$-neutrophil accumulation in rabbit myocardium by MoA ischemic injury. J. Mol. Cell. Cardiol. 20:S33. (Abstr.)

5. Seewaldt-Becker, E., R. Rothlein, and J. W. Dammgen. 1989. CDw 18 dependent adhesion of leukocytes to endothelium and its relevance for cardiac reperfusion. In Leukocyte Adhesion Molecules: Structure, Function, and Regulation. T. A. Springer, D. C. Anderson, A. S. Rosenthal, and R. Rothlein, editors. Springer-Verlag New York Inc., New York. 138-148.

6. Simpson, P. J., R. F. Todd, III, J. K. Mickelson, J. C. Fantone, K. P. Gallagher, K. A. Lee, Y. Tamura, M. Cronin, and B. R. Lucchesi. 1990. Sustained limitation of myocardial reperfusion injury by a monoclonal antibody that alters leukocyte function. Circulation. 81:226-237.

7. Tanaka, M., S. E. Brooks, G. P. Fitzharris, R. C. Stoler, R. B. Jennings, and K. A. Reimer. 1990. Effect of the IB4 anti-CD18 antibody on myocardial PMN accumulation and infarct size in dogs. FASEB (Fed. Am. Soc. Exp. Biol.) J. 4:A1020. (Abstr.)

8. Dreyer, W. J., L. H. Michael, M. S. West, C. W. Smith, R. Rothlein, R. D. Rossen, D. C. Anderson, and M. L. Entman. 1991. Neutrophil accumulation in ischemic canine myocardium: insights into the time course, distribution, and mechanism of localization during early reperfusion. Circulation. 84:400-411.

9. Ma, X.-L., P. S. Tsao, and A. M. Lefer. 1991. Antibody to CD-18 exerts endothelial and cardiac protective effects in myocardial ischemia and reperfusion. J. Clin. Invest. 88:1237-1243.

10. Lefer, D. J., M. L. Suresh, M. L. Shandelya, C. V. Serrano, L. C. Becker, P. Kuppusamy, and J. L. Zweier. 1993. Cardioprotective actions of a monoclonal antibody against CD-18 in myocardial ischemia-reperfusion injury. Circulation. 88:1779-1787.

11. Hill, J. H., and P. A. Ward. 1971. The phlogistic role of C3 leukotactic fragment in myocardial infarcts of rats. J. Exp. Med. 133:885-900.

12. Rossen, R. D., J. L. Swain, L. H. Michael, S. Weakley, E. Giannini, and M. L. Entman. 1985. Selective accumulation of the first component of complement and leukocytes in ischemic canine heart muscle: a possible initiator of an extra myocardial mechanism of ischemic injury. Circ. Res. 57:119-130.

13. Rossen, R. D., L. H. Michael, A. Kagiyama, H. E. Savage, G. Hanson, J. N. Reisbery, J. N. Moake, S. H. Kim, S. Weakly, E. Giannini, and M. L. Entman. 1988. Mechanism of complement activation following coronary artery occlusion: evidence that myocardial ischemia causes release of constituents of myocardial subcellular origin which complex with the first component of complement. Circ. Res. 62:572-584.

14. Pinckard, R. N., M. S. Olson, P. C. Giclas, R. Terry, J. T. Boyer, and R. A. O'Rourke. 1975. Consumption of classical complement components by heart subcellular membranes in vitro and in patients after acute myocardial infarction. $J$. Clin. Invest. 56:740-750.

15. Crawford, M. H., F. L. Grover, W. P. Kolb, C. A. McMahan, R. A. O'Rourke, L. M. McManus, and R. N. Pinckard. 1988. Complement and neutrophil activation in the pathogenesis of ischemic myocardial injury. Circulation. 78:1449-1458.

16. Dreyer, W. J., L. H. Michael, T. Nguyen, C. W. Smith, D. C. Anderson, M. L. Entman, and R. D. Rossen. 1992. Kinetics of C5a release in cardic lymph of dogs experiencing coronary artery ischemia-reperfusion injury. Circ. Res. 71:1518-1524.

17. Dreyer, W. J., C. W. Smith, L. H. Michael, R. D. Rossen, B. J. Hughes, M. L. Entman, and D. C. Anderson. 1989. Canine neutrophil activation by cardiac lymph obtained during reperfusion of ischemic myocardium. Circ. Res. 65:17511762.

18. Weisman, H. F., T. Barton, M. K. Leppo, H. C. Marsh, Jr., G. R. Carson, M. F. Concino, M. P. Boyle, K. H. Roux, M. L. Weisfeldt, and D. T. Fearon. 1990. Soluble human complement receptor type 1: In vivo inhibitor of complement 
suppressing post-ischemic myocardial inflammation and necrosis. Science (Wash DC). 249:146-151.

19. Shandelya, S. M. L., P. Kuppusamy, A. Herskowitz, M. L. Weisfeldt, and J. L. Zweier. 1993. Soluble complement receptor type 1 inhibits the complemen pathway and prevents contractile failure in the postischemic heart. Circulation. 88:2812-2826.

20. Youker, K., C. W. Smith, D. C. Anderson, D. Miller, L. H. Michael, R. D. Rossen, and M. L. Entman. 1992. Neutrophil adherence to isolated adul cardiac myocytes. Induction by cardiac lymph collected during ischemia and reperfusion. J. Clin. Invest. 89:602-609.

21. Kukielka, G. L., H. K. Hawkins, L. H. Michael, A. M. Manning, C. Lane, M. L. Entman, C. W. Smith, and D. C. Anderson. 1993. Regulation of intercellula adhesion molecule-1 (ICAM-1) in ischemic and reperfused canine myocardium. J. Clin. Invest. 92:1504-1516.

22. Huber, A. R., S. L. Kunkel, R. F. Todd, III, and S. J. Weiss. 1991 Regulation of transendothelial neutrophil migration by endogenous interleukin-8. Science (Wash. DC). 254:99-105.

23. Kuijpers, T. W., B. C. Hakkert, M. H. L. Hart, and D. Roos. 1992 Neutrophil migration across monolayers of cytokine-prestimulated endothelia cells. A role for platelet-activating factor and IL-8. J. Cell Biol. 117:565-572.

24. Baggiolini, M., B. Dewald, and A. Walz. 1992. Interleukin-8 and related chemotactic cytokines. In Inflammation: Basic Principles and Clinical Correlates J. I. Gallin, I. M. Goldstein, and R. Snyderman, editors. Raven Press, New York. 247-263.

25. Baggiolini, M., A. Walz, and S. L. Kunkel. 1989. Neutrophil-activating peptide-1/interleukin 8 , a novel cytokine that activates neutrophils. J. Clin. Invest. 84:1045-1049.

26. Miller, M. D., and M. S. Krangel. 1992. Biology and biochemistry of the chemokines: a family of chemotactic and inflammatory cytokines. Crit. Rev. Immunol. 12:17-46.

27. Springer, T. A. 1994. Traffic signals for lymphocyte recirculation and leukocyte emigration: the multistep paradigm. Cell. 76:301-314.

28. Sekido, N., N. Mukaida, A. Harada, I. Nakanishi, Y. Watanabe, and K. Matsushima. 1993. Prevention of lung reperfusion injury in rabbits by a monoclonal antibody against interleukin-8. Nature (Lond.). 365:654-657.

29. Sambrook, J., E. F. Fritsch, and T. Maniatis. 1989. Molecular Cloning A Laboratory Manual. Cold Spring Harbor Laboratory, Cold Spring Harbor, NY $545 \mathrm{pp}$.

30. Sanger, F., S. Nicklen, and A. R. Coulson. 1977. DNA sequencing with chain terminating inhibitors. Proc. Natl. Acad. Sci. USA. 74:5463-5468.

31. Schagger, H., and G. von Jagow. 1987. Tricine-sodium dodecyl sulfatepolyacrylamide gel electrophoresis for the separation of proteins in the range from 1 to $100 \mathrm{kDa}$. Anal. Biochem. 166:368-379.

32. Smith, C. W., S. D. Marlin, R. Rothlein, C. Toman, and D. C. Anderson. 1989. Cooperative interactions of LFA-1 and Mac-1 with intercellular adhesion molecule-1 in facilitating adherence and transendothelial migration of human neutrophils in vitro. J. Clin. Invest. 83:2008-2017.

33. Smith, C. W., R. Rothlein, B. J. Hughes, M. M. Mariscalco, F. C. Schmalstieg, and D. C. Anderson. 1988. Recognition of an endothelial determinant fo CD18-dependent human neutrophil adherence and transendothelial migration. $J$. Clin. Invest. 82:1746-1756.

34. Entman, M. L., K. A. Youker, S. B. Shappell, C. Siegel, R. Rothlein W. J. Dreyer, F. C. Schmalstieg, and C. W. Smith. 1990. Neutrophil adherence to isolated adult canine myocytes. Evidence for a CD18-dependent mechanism. J. Clin. Invest. 85:1497-1506.

35. Smith, C. W., J. C. Hollers, R. A. Patrick, and C. Hassett. 1979. Motility and adhesiveness in human neutrophils. Effects of chemotactic factors. J. Clin Invest. 63:221-229.

36. Rot, A. 1993. Neutrophil attractant/activation protein-1 (interleukin-8) induces in vitro neutrophil migration by haptotactic mechanism. Eur. J. Immunol. 23:303-306.

37. Smith, C. W. M. L. Entman, C. L. Lane, A. L. Beaudet, T. I. Ty, K. A Youker, H. K. Hawkins, and D. C. Anderson. 1991. Adherence of neutrophils to canine cardiac myocytes in vitro is dependent on intercellular adhesion molecule1. J. Clin. Invest. 88:1216-1223.

38. Shappell, S. B., C. Toman, D. C. Anderson, A. A. Taylor, M. L. Entman, and C. W. Smith. 1990. Mac-1 (CD11b/CD18) mediates adherence-dependent hydrogen peroxide production by human and canine neutrophils. J. Immunol. 144:2702-2711.

39. Entman, M. L., K. A. Youker, T. Shoji, G. L. Kukielka, S. B. Shappell, A. A. Taylor, and C. W. Smith. 1992. Neutrophil induced oxidative injury of cardiac myocytes. A compartmented system requiring CD11b/CD18-ICAM-1 adherence. J. Clin. Invest. 90:1335-1345.

40. Heymann, M. A., B. D. Payne, J. I. E. Hoffman, and A. M. Rudolph. 1977. Blood flow measurements with radionuclide-labeled particles. Prog. Cardiovasc. Dis. XX:55-78.

41. Goddard-Finegold, J., and L. H. Michael. 1984. Cerebral blood flow and experimental intraventricular hemorrhage. Pediatr. Res. 18:7-11.

42. Chomczynski, P., and N. Sacchi. 1987. Single-step method of RNA isola- tion by acid guanidinium thiocyanate-phenol-chloroform extraction. Anal. Bio chem. 162:156-159.

43. Kozak, M. 1986. Point mutations define a sequence flanking the AUG initiator codon that modulates translation by eukaryotic ribosomes. Cell. 44:283292.

44. Kozak, M. 1987. An analysis of 5'-noncoding sequences from 699 vertebrate messenger RNAs. Nucleic Acids Res. 15:8125-8148.

45. Kowalski, J., and D. T. Denhardt. 1989. Regulation of the mRNA for monocyte-derived neutrophil-activating peptide in differentiating HL60 promyelocytes. Mol. Cell. Biol. 9:1946-1957.

46. Goodman, R. B., D. C. Foster, S. L. Mathewes, S. G. Osborn, J. L. Kuijper, J. W. Forstrom, and T. R. Martin. 1992. Molecular cloning of porcine alveolar macrophage-derived neutrophil chemotactic factors I and II: identification of porcine IL-8 and another intercrine- $\alpha$ protein. Biochemistry. 31:10483-10490.

47. Yoshimura, T., and N. Yuhki. 1991. Neutrophil attractant/activation protein-1 and monocyte chemoattractant protein-1 in rabbit: cDNA cloning and their expression in spleen cells. J. Immunol. 146:3483-3488.

48. von Heijne, G. 1990. The signal peptide. J. Membr. Biol. 115:195-201.

49. Yoshimura, T., K. Matsushima, S. Tanaka, E. A. Robinson, E. Appella J. J. Oppenheim, and E. J. Leonard. 1987. Purification of a human monocytederived neutrophil chemotactic factor that has peptide sequence similarity to other host defense cytokines. Proc. Natl. Acad. Sci. USA. 84:9233-9237.

50. Lindley, I., H. Aschauer, J.-M. Seifert, C. Lam, W. Brunowsky, E. Kownatzki, M. Thelen, P. Peveri, B. Dewald, V. von Tscharner, et al. 1988. Synthesis and expression in Escherichia coli of the gene encoding monocyte-derived neutrophil-activating factor: biological equivalence between natural and recombinant neutrophil-activating factor. Proc. Natl. Acad. Sci. USA. 85:9199-9203.

51. Herbert, C. A., F. W. Luscinskas, J.-M. Kiely, E. A. Luis, W. C. Darbonne G. L. Bennett, C. C. Liu, M. S. Obin, M. A. Gimbrone, Jr., and J. B. Baker 1990. Endothelial and leukocyte forms of IL-8. J. Immunol. 145:3033-3040.

52. Birnstiel, M. L., M. Busslinger, and K. Strub. 1985. Transcription termination and $3^{\prime}$ processing: the end is in site! Cell. 41:349-359.

53. Caput, D., B. Beutler, K. Hartog, R. Thayer, S. Brown-Shimer, and A Cerami. 1986. Identification of a common nucleotide sequence in the 3 '-untranslated region of mRNA molecules specifying inflammatory mediators. Proc. Natl. Acad. Sci. USA. 83:1670-1674.

54. Clemens, M. J. 1987. A potential role for RNA transcribed from B2 repeats in the regulation of mRNA stability. Cell. 49:157-158.

55. Shaw, G., and R. Kamen. 1986. A conserved au sequence from the $3^{\prime}$ untranslated region of GM-CSF mRNA mediates selective mRNA degradation. Cell. 46:659-667.

56. Beutler, B., P. Thompson, J. Keyes, K. Hagerty, and D. Crawford. 1988. Assay of a ribonuclease that preferentially hydrolyses mRNAs containing cytokine-derived ua-rich instability sequences. Biochem. Biophys. Res. Commun. 152:973-980.

57. Muller, W. E. G., H. Slor, K. Pfeifer, P. Huhn, A. Bek, S. Orsulic, H. Ushijima, and H. C. Schroder. 1992. Association of AUUUA-binding protein with A + U-rich mRNA during nucleocytoplasmic transport. J. Mol. Biol. 226:721-733

58. Matsushima, K., K. Morishita, T. Yoshimura, S. Lavu, Y. Kobayashi, W. Lew, E. Apella, H. F. Kung, E. J. Leonard, and J. J. Oppenheim. 1988. Molecular cloning of a human monocyte-derived neutrophil chemotactic factor (MDNCF) and the induction of MDNCF mRNA by interleukin 1 and tumor necrosis factor. J. Exp. Med. 167:1883-1893.

59. Detmers, P. A., S. K. Lo, E. Olsen-Egbert, A. Walz, M. Baggiolini, and Z. A. Cohn. 1990. Neutrophil-activating protein 1/interleukin 8 stimulates the binding activity of the leukocyte adhesion receptor $\mathrm{CD} 11 \mathrm{~b} / \mathrm{CD} 18$ on human neutrophils. J. Exp. Med. 171:1155-1162.

60. Strieter, R. M., S. L. Kunkel, H. J. Showell, D. G. Remick, S. H. Phan P. A. Ward, and R. M. Marks. 1989. Endothelial cell gene expression of a neutrophil chemotactic factor by TNF-alpha, LPS, and IL-1-beta. Science (Wash DC). 243:1467-1469.

61. Strieter, R. M., S. I. Kunkel, H. J. Showell, and R. M. Marks. 1988. Monokine-induced gene expression of a human endothelial cell-derived neutrophi chemotactic factor. Biochem. Biophys. Res. Commun. 156:1340-1345.

62. Strieter, R. M., K. Kasahara, R. M. Allen, T. J. Standiford, M. W. Rolfe F. S. Becker, S. W. Chensue, and S. L. Kunkel. 1992. Cytokine-induced neutrophil-derived interleukin-8. Am. J. Pathol. 141:397-407.

63. Carlos, T., N. Kovach, B. Schwartz, M. Rosa, B. Newman, E. Wayner, C. Benjamin, L. Osborn, R. Lobb, and J. Harlan. 1991. Human monocytes bind to two cytokine-induced adhesive ligands on cultured human endothelial cells: endothelial-leukocyte adhesion molecule-1 and vascular cell adhesion molecule1. Blood. 77:2266-2271.

64. Gusella, G. L., T. Musso, M. C. Bosco, I. Espinoza-Delgado, K. Matsushima, and L. Varesio. 1993. IL-2 up-regulates but IFN-gamma suppresses IL-8 expression in human monocytes. J. Immunol. 151:2725-2732.

65. Rot, A. 1991. Chemotactic potency of recombinant human neutrophil attractant/activation protein-1 (interleukin-8) for polymorphonuclear leukocytes of different species. Cytokine. 3:21-27. 
66. Zwahlen, R. D., D. Spreng, and M. Wyder-Walther. 1994. In vitro and in vivo activity of human interleukin-8 in dogs. Vet. Pathol. 31:61-66.

67. Ember, J. A., S. D. Sanderson, T. E. Hugli, and E. L. Morgan. 1994 Induction of interleukin-8 synthesis from monocytes by human C5a anaphylatoxin Am. J. Pathol. 144:393-403.

68. Laudanna, C., G. Constantin, P. Baron, E. Scarpini, G. Scarlato, G. Cabrini, C. Dechecchi, F. Rossi, M. A. Cassatella, and G. Berton. 1994. Sulfatides trigger increase of cytosolic free calcium and enhanced expression of tumor necrosis factor- $\alpha$ and interleukin-8 mRNA in human neutrophils. J. Biol. Chem. 269:4021 4026.

69. Ma, X.-L., A. S. Weyrich, D. J. Lefer, M. Buerke, K. H. Albertine, T. K Kishimoto, and A. M. Lefer. 1993. Monoclonal antibody to L-selectin attenuates neutrophil accumulation and protects ischemic reperfused cat myocardium. Circulation. 88:649-658.
70. Karakurum, M., R. Shreeniwas, J. Chen, D. Pinsky, S.-D. Yan, M. Anderson, K. Sunouchi, J. Major, T. Hamilton, K. Kuwabara, et al. 1994. Hypoxic induction of interleukin-8 gene expression in human endothelial cells. J. Clin. Invest. 93:1564-1570.

71. Furie, M. B., M. C. A. Tancinco, and C. W. Smith. 1991. Monoclonal antibodies to leukocyte integrins $\mathrm{CD} 11 \mathrm{a} / \mathrm{CD} 18$ and $\mathrm{CD} 11 \mathrm{~b} / \mathrm{CD} 18$ or intercellular adhesion molecule-1 (ICAM-1) inhibit chemoattractant-stimulated neutrophil transendothelial migration in vitro. Blood. 78:2089-2097.

72. Hechtman, D. H., M. I. Cybulsky, H. J. Fuchs, J. B. Baker, and M A. Gimbrone, Jr. 1991. Intravascular IL-8. Inhibitor of polymorphonuclear leukocyte accumulation at sites of acute inflammation. J. Immunol. 147:883892.

73. Rot, A. 1993. Binding of neutrophil attractant/activation protein-1 (interleukin 8) to resident dermal cells. Cytokine. 4:347-352. 